\title{
APLICACIÓN DE LOS PRINCIPIOS DE GOBIERNOS CORPORATIVOS A SOCIEDADES NO COTIZADAS EN CHILE. UNA APROXIMACIÓN DESDE EL DERECHO SOCIETARIO EUROPEO Y COMPARADO*
}

\author{
APPLICATION OF THE PRINCIPLES \\ OF CORPORATE GOVERNANCE FOR \\ UNLISTED COMPANIES IN CHILE. AN \\ APPROACH FROM EUROPEAN AND \\ COMPARATIVE CORPORATIVE LAW
}

\author{
María Fernanda Vásquez-Palma** \\ Álvaro Vidal-Olivares**** \\ Fecha de recepción: 07 de marzo de 2016 \\ Fecha de aceptación: 23 de mayo de 2016 \\ Disponible en linea: 30 de noviembre de 2016
}

\section{Para citar este artículo/To cite this article}

\begin{abstract}
Vásquez-Palma, María Fernanda \& Vidal-Olivares, Álvaro, Aplicación de los principios de gobiernos corporativos a sociedades no cotizadas en Chile. Una aproximación desde el derecho societario europeo y comparado, 133 Vniversitas, 383-444 (2016). http://dx.doi.org/10.11144/Javeriana.vj133.apgc doi:10.11144/Javeriana.vj133.apgc
\end{abstract}

* Este artículo se enmarca en el proyecto Anillo SOC 1406, titulado Mecanismos alternativos de resolución de conflictos como herramientas para modernizar la justicia. Una construcción dogmática desde un análisis multidisciplinario, financiado por la Comisión Nacional de Investigación Científica y Tecnológica, CONICYT; y en el proyecto La posible extensión de los principios de gobiernos corporativos a las sociedades no cotizadas. Análisis de la realidad chilena a partir de los avances experimentados en derecho comparado, financiado por el Centro de Gobiernos Corporativos de la Pontificia Universidad Católica de Chile.

** Profesora de derecho comercial, Universidad de Talca. Doctora en derecho, Universidad Complutense de Madrid. Contacto:mfvasquez@utalca.cl

*** Profesor de derecho civil, Pontificia Universidad Católica de Valparaíso. Doctor en derecho, Universidad Autónoma de Madrid. Contacto: alvaro.vidal@pucv.cl 


\section{RESUMEN}

Dada la importancia que han adquirido los principios de buen gobierno corporativo (en adelante, $\mathrm{PBGC}$ ), que rigen las sociedades que cotizan en bolsa y que operan como regla de conducta comercial y punto de referencia para el fortalecimiento de los mecanismos de control y supervisión de la administración de este tipo societario, este trabajo plantea la posibilidad de extensión de los PBGC a las sociedades que no cotizan en los mercados de valores, juntos a sus respectivos fundamentos.

Palabras claves: principios; gobiernos corporativos; sociedades no cotizadas 


\section{ABSTRACT}

Given the importance acquired the Principles of Good Corporate Governance (PGCG) that governing of listed companies and operate as a rule of business conduct and reference point for the strengthening of the mechanisms of control and supervision of the administration of this type of company partnerships this work raises the possibility of extending the PGCG to unlisted markets, together with their respective justification.

Keywords: principles; government corporate; unlisted companies

\section{SUMARIO}

INTRODUCCIÓN.- I. SOBRE LOS PRINCIPIOS QUE RIGEN LOS GOBIERNOS CORPORATIVOS: unA miRADA DE CONTEXTO.- A. Aspectos esenciales de los principios de buen gobierno corporativo. Noción, modelos, objetivos.- II. SOBRE LA EXTENSIÓN DE LOS PRINCIPIOS DE BUEN GOBIERNO CORPORATIVO EN Las sociedades no Cotizadas.- A. Sociedad no cotizada.- B. ¿Por qué y cómo extender los PBGC a las sociedades no cotizadas? Fundamentos e instrumentos. - 1. Justificación de la extensión de los PBGC a la sociedad no cotizada.- 2. Ámbito subjetivo, principios aplicables e instrumentos idóneos.- 3. Aplicación de los PBGC a la sociedad no cotizada.- III. LA PROMOCIÓN DEL BUEN GOBIERNO CORPORATIVO A LAS SOCIEDADES NO COTIZADAS EN EUROPA.- IV. REVISIÓN DE LA SITUACIÓN DEL DERECHO SOCIETARIO CHILENO.A. Incorporación del buen gobierno a la legislación chilena.- B. ¿Es posible extrapolar los principios de buen gobierno corporativo a las sociedades no cotizadas en la legislación chilena?- C. Situación particular de ciertas sociedades anónimas especiales: compañías de seguros.- V. CONSTRUCCIÓN DE UNA PROPUESTA PARA LA APLICACIÓN DEL BUEN GOBIERNO CORPORATIVO A LAS SOCIEDADES NO COTIZADAS.- CONCLUSIONES.- BibLIOGRAFÍA. 


\section{INTRODUCCIÓN}

Asumiendo la importancia que han adquirido las reglas que rigen los gobiernos corporativos de las sociedades que cotizan en bolsa, y el rol fundamental que en la materia juegan los principios de buen gobierno corporativo (en adelante, $\mathrm{PBGC}$ ), como regla de conducta comercial para el fortalecimiento de los mecanismos de control de la administración de este tipo societario, este trabajo tiene por objeto dar respuesta a la siguiente interrogante: ¿podría extenderse la aplicación de los principios a las sociedades chilenas que no cotizan en los mercados de valores?, ¿se justificaría su aplicación?, ¿en qué supuestos?, ¿cómo podrían aplicarse?

Partimos de la hipótesis de una respuesta afirmativa, primero, por el valor agregado que aportan estos principios a toda sociedad $\mathrm{y}$, segundo, porque no se avizoran buenas razones para oponerse a su aplicación, muy por el contrario. Sin embargo, es necesario —y allí reside la justificación de este trabajo — analizar cuáles son los fundamentos en que descansaría tal extrapolación y examinar reflexivamente su pertinencia, conveniencia y operatividad. En el camino propuesto, surgen diversas inquietudes sobre cuáles son los instrumentos de aplicación más efectivos y sus posibilidades concretas de implementación. En este orden de ideas, debe desentrañarse en qué tipo de sociedades es posible fomentar su aplicación, qué principios podrían aplicarse y con qué herramientas. Estas son las preguntas que intentaremos responder en las siguientes líneas.

Este trabajo se divide en dos secciones. En la primera examinaremos, desde una óptica general, los principios de buen gobierno corporativo y su extensión a las sociedades no cotizadas; en la segunda, nos abocaremos a la situación del derecho chileno y a la conveniencia de extender esos principios a esta clase de sociedades. Finalizaremos con un breve cuerpo de conclusiones. 


\section{SOBRE LOS PRINCIPIOS QUE RIGEN LOS GOBIERNOS CORPORATIVOS: UNA MIRADA DE CONTEXTO}

\section{A. Aspectos esenciales de los principios de buen gobierno corporativo. Noción, modelos, objetivos}

En general, se entiende por gobierno corporativo el modo o manera en que las empresas son dirigidas y controladas. Otro modo de definirlo es como el conjunto de normas, principios y procedimientos que regulan la estructura y el funcionamiento de los órganos de gobierno de una sociedad. Las partes implicadas en el proceso de gobierno son la alta dirección, los administradores, los socios y otros grupos de interés o stakeholders, de manera que un modelo de gobierno corporativo sólido debiera articular eficientemente las relaciones e intereses de todos esos colectivos defendiendo en último término el interés social, entendido este como la creación de valor sostenible a largo plazo.

No hay un modelo único de gobierno corporativo, el trabajo para su construcción ha sido desplegado por diversas instituciones, lo que ha permitido identificar sus principales elementos ${ }^{1}$. Entre ellas, la Organización para la Cooperación y el Desarrollo Económicos (en adelante, $\mathrm{OCDE})^{2}$ ha sido quizá la más relevante al diseñar los "principios de buen gobierno corporativo"3. Estos

1 El concepto de gobierno corporativo apareció en 1976 en los países más desarrollados del oeste de Europa, en Canadá, Estados Unidos y Australia, como consecuencia de la necesidad que tenían los accionistas minoritarios de las empresas de conocer el estado de su inversión; esto es, querían saber qué se estaba haciendo con su dinero y cuáles eran las expectativas futuras. Esto hizo que los accionistas mayoritarios de un negocio y sus administradores iniciaran un proceso de apertura, profesionalización y transparencia en el manejo de la información. http:// www.supersociedades.gov.co/inspeccion-vigilancia-y-control/gobierno-corporativo-y-rse/ documentos/Documentos\%20RSE/Historia $\% 20 \mathrm{del} \% 20$ Gobierno\%20Corporativo\%20(14). pdf

2 www.ocde.org

3 Dado que no hay un concepto unívoco sobre gobierno corporativo, aquel dependerá de la perspectiva que se utilice. Esto da lugar a dos modelos de gobierno corporativo; por un lado, el legalista que ve la empresa como un conjunto de contratos con el propósito exclusivo de servir a sus accionistas y, por el otro, el comunitarista que considera la empresa como una entidad legal independiente con una responsabilidad más amplia. M. SAva B. Thomas, Gobierno corporativo en los Estados Unidos a comienzos del siglo XXI y su posición en el ámbito global, 29 Revista Chilena de Derecho, 3, Actas de las I Jornadas de Derecho de la Empresa, Santiago, 24-25 de octubre de 2001 (septiembre-diciembre de 2002), 661-671 (2002). Disponible en: https://dialnet.unirioja.es/servlet/articulo?codigo=2650251. En Estados Unidos, el término se refiere, en general, a la relación entre los ejecutivos que manejan una empresa pública, 
principios surgen con la finalidad de ayudar a los gobiernos de los países miembros y no miembros de la OCDE en la tarea de evaluar y perfeccionar los marcos legales, institucionales y reglamentarios, aplicables a los gobiernos corporativos en sus respectivos países, para ofrecer orientación y sugerencias a las bolsas de valores, los inversores, las sociedades y demás partes que intervienen en el desarrollo de un modelo de buen gobierno corporativo ${ }^{4}$.

Muchos factores afectan los procesos de gobierno y de toma de decisiones en las empresas. A pesar de su importancia en el éxito de las mismas a largo plazo, los principios se centran en los problemas de gobierno que se generan por la separación entre propiedad y control. No se trata de una cuestión exclusivamente circunscrita a las relaciones entre los accionistas y el cuerpo directivo; el gobierno de una sociedad también se puede ver afectado por las relaciones que se generan con los accionistas controladores, que pueden ser personas individuales, sociedades familiares, alianzas en bloque $u$ otras sociedades que actúan por medio de un grupo de empresas o de participaciones cruzadas, y que pueden influir significativamente en el comportamiento de la sociedad. De otra parte, también debemos considerar los intereses de los inversores y terceros vinculados a la sociedad, que — por sus especiales intereses - esperan un buen gobierno societario. En tal sentido, cada actor partícipe de la relación que se genera entre la empresa y el mercado pretende algo particular: los accionistas individuales normalmente no estarán interesados en ejercitar derechos de gobierno, pero sí les preocupa la posibilidad de no obtener un trato justo por parte de los accionistas con poder de control y del cuerpo directivo; los acreedores, por su parte, pretenden que sus acreencias se cumplan y, desde este sitial, sirven como agentes supervisores de los resultados de la sociedad;

su directorio y sus accionistas. John Farrar, The New Financial Architecture and Effective Corporate Governance, 33 The International Lawyer, 4, 927-954 (1999).

4 Los principios de gobierno corporativo emergen como respuesta a un llamado del Consejo de la OCDE tras una reunión ministerial, celebrada el 27 y 28 de abril de 1998. Esta cumbre concluyó que se requería el desarrollo y elaboración de un conjunto de normas y directrices en materia de gobierno corporativo, con la participación de gobiernos nacionales, de otras organizaciones interesadas y del sector privado. Desde la aprobación de los Principios en 1999, estos han constituido la base de las iniciativas en el ámbito del gobierno corporativo puestas en práctica tanto en los países de la OCDE como en los países no-miembros (versión 2004). Organización para la Cooperación y el Desarrollo Económicos, OCDE, Principios de gobierno corporativo (Organización para la Cooperación y el Desarrollo Económicos, OCDE, París, 2004). Disponible en: http://www.oecd.org/daf/ca/corporategovernanceprinciples/37191543.pdf 
los empleados y terceros también desempeñan una función importante a la hora de contribuir al éxito del interés social a largo plazo.

Tanto el papel de cada uno de estos participantes como la interacción entre ellos varían enormemente en cada legislación. Así, por ejemplo, en algunos países, los empleados cuentan con garantías legales con independencia de sus derechos de propiedad; en otras legislaciones, se brinda mayor relevancia a cuestiones relativas al medio ambiente o de carácter ético. Por consiguiente, los principios surgen para brindar un marco común que pueda ser tenido en consideración por los Estados como modelo legislativo y por las propias sociedades, al momento de incorporarlos convencionalmente.

Entre estos principios destacan los siguientes:

1. Principios para garantizar la base de un marco eficaz para el gobierno corporativo, con el objeto de promover la transparencia y eficacia de los mercados, ser coherente con el Estado de Derecho y articular de forma clara el reparto de responsabilidades entre las distintas autoridades supervisoras, reglamentarias y ejecutivas.

2. Principios que protegen los derechos de los accionistas, para amparar y facilitar el ejercicio de sus derechos, y también el ejercicio de acciones de responsabilidad, frente a su vulneración.

3. Tratamiento equitativo de los accionistas. Este marco jurídico garantiza un trato equitativo a todos los accionistas, incluidos los minoritarios y los extranjeros.

4. Regulación de las partes interesadas. El gobierno corporativo deberá reconocer los derechos de las partes interesadas establecidos por ley o por medio de acuerdos mutuos, y fomentar la cooperación activa entre sociedades y aquellas con vistas a la creación de riqueza y empleo, y a facilitar la sostenibilidad de empresas sanas desde el punto de vista financiero.

5. Divulgación de datos y transparencia. Se debe garantizar la divulgación oportuna y precisa de todas las cuestiones materiales relativas a la sociedad, incluida la situación financiera, los resultados, la titularidad y el gobierno de la empresa, con el objeto de proveer información simétrica a las partes y terceros interesados.

6. Responsabilidades del consejo. El gobierno corporativo deberá asegurar la orientación estratégica de la empresa, el control 
efectivo de la dirección ejecutiva del consejo directivo y la responsabilidad de este frente a la empresa y los accionistas.

En cuanto al destinatario, si bien la OCDE expresa que los PBGC centran su atención en las sociedades con cotización oficial, tanto financieras como no financieras, también reconoce que podrían constituir un instrumento muy útil para mejorar el gobierno corporativo en sociedades sin cotización oficial, privadas o de propiedad del Estado5. Lo anterior también ha sido respaldado por el Libro Verde. La normativa de gobierno corporativo de la Unión Europea ${ }^{6}$. Este Green Paper. The EU Corporate Governance Framework instaba a expandir los códigos de buen gobierno corporativo a las sociedades no cotizadas, y a consultar si era preciso incorporar normas específicas en la materia. El Green Paper de la Unión Europea consideraba que si bien las leyes de obligado cumplimiento ya concretaban determinadas obligaciones y algunas compañías no cotizadas ya incorporaban en su normativa interna algunas de las obligaciones y recomendaciones no obligatorias aplicables a las sociedades cotizadas, aquellas no seguían la mayor parte de estas recomendaciones. Además, se resaltaba la importancia, por su tamaño, de buena parte de las sociedades no cotizadas, entre ellas muchas empresas familiares, y se reflexionaba sobre el coste de implantar determinadas recomendaciones en las empresas pequeñas y medianas. Finalmente, se recordaba la existencia de algunas iniciativas europeas, públicas y privadas, que habían desembocado en diferentes propuestas de códigos para compañías no cotizadas?

5 La OCDE y los gobiernos que la conforman reconocen con una claridad cada vez mayor la sinergia entre las políticas macroeconómicas y las estructurales a la hora de alcanzar los objetivos políticos fundamentales de diversas sociedades. Organización para la Cooperación y el Desarrollo Económicos, OCDE, Principios de gobierno corporativo (Organización para la Cooperación y el Desarrollo Económicos, OCDE, París, 2004). Disponible en: http://www. oecd.org/daf/ca/corporategovernanceprinciples/37191543.pdf

6 Comisión Europea, $\mathrm{COM(2011),} 164$ final, Libro Verde. La normativa de gobierno corporativo de la Unión Europea (Comisión Europea, Bruselas, 2011). Disponible en: http://ec.europa.eu/ internal_market/company/docs/modern/com2011-164_es.pdf, http://ec.europa.eu/internal_ market/company/docs/modern/com2011-164_en.pdf

7 Pablo HafNer analiza las distintas propuestas y códigos de este tipo existentes en Europa. Pablo Hafner, Iniciativas públicas y privadas de códigos de buen gobierno para empresas no cotizadas en Europa (Centro de Buen Gobierno IE/GT, Iberdrola, IE, Mutua Madrileña \& PwC, Madrid, 2015). Disponible en: http://www.centrobuengobierno.ie.edu/2016/04/01/iniciativaspublicas-y-privadas-de-codigos-de-buen-gobierno-para-empresas-no-cotizadas-en-europa/. TOMÁs Garicano-RoJas \& Pablo Hafner, Recomendaciones de buen gobierno corporativo para empresas no cotizadas (Centro de Buen Gobierno, Madrid, 2016). Disponible en: http://www. 
En general, el estudio de los PBGC ha cobrado una innegable importancia en estos últimos años ${ }^{8}$, y se ha instaurado como una de las materias de mayor interés, no solo dogmático sino también práctico, del moderno derecho societario ${ }^{9}$. La razón es la creciente constatación de que el poder detentado por la administración de las sociedades reclama límites, en especial debido a la ocurrencia de escándalos financieros de elevada repercusión y connotación pública que han evidenciado la vulnerabilidad de los mecanismos tradicionales de control y supervisión, a lo que se suma la pérdida de confianza respecto de la eficacia de los modelos vigentes. Lo anterior ha desatado una singular cruzada para fortalecer la transparencia en el gobierno corporativo, principalmente en aquellas sociedades que cotizan en el mercado de valores, ante todo por la modalidad de financiamiento de este tipo societario ${ }^{10}$. En esta

centrobuengobierno.ie.edu/wp-content/uploads/sites/87/2013/11/Recomendaciones-BuenGobierno-Empresas-No-cotizadas-actualizado.pdf

8 El interés actual surge en mayo de 1992, fecha en que se hizo público en el Reino Unido el ya histórico Informe Cadbury (Informe del Comité sobre los aspectos financieros del gobierno corporativo) Financial Reporting Council, London Stock Exchange \& The Committee on the Financial Aspects of Corporate Governance, Report of the Committee on The Financial Aspects of Corporate Governance, Cadbury Report [sir Adrian Cadbury] (May 1992). Disponible en: http://cadbury.cjbs.archios.info/report. Desde los orígenes de la holandesa Vereenigde Oostindische Compagnie, VOC (Compañía de las Indias Orientales), el 20 de marzo de 1602, el debate sobre el gobierno corporativo en Europa se ha centrado en los sistemas de control efectivo de la gerencia de una empresa. Sobre los aspectos históricos, Santiago HierroAnibarro, Gobierno corporativo sin mercado de valores, en Gobierno corporativo en sociedades no cotizadas, 17-33, 18 ss. (SAntiago Hierro-Anibarro, dir., Marcial Pons, Ediciones Jurídicas y Sociales, Madrid, Barcelona, Buenos Aires, São Paulo, 2014).

9 Se trata de una materia que depende de muchos factores, no solo de la cualidad e integridad de los miembros del consejo de administración y la determinación de sus deberes de diligencia y fidelidad, sino también del tamaño adecuado del órgano y de su organización, sus respectivos comités (sus nombramientos, remuneraciones y auditoría); buen funcionamiento de los canales comunicacionales; de la estrecha colaboración con los auditores de cuentas; además de muchas otras circunstancias. De este modo, no hay una solución única o ideal porque el derecho de sociedades se desarrolla de una forma diferente en cada sistema (path dependence). SANTIAGO Hierro-Anibarro, coord., Estudios de derecho de sociedades y del mercado de valores, Libro homenaje a Klaus J. Hopt (Marcial Pons, Madrid, 2010).

10 De la mano de ello, en la mayoría de los países preocupados por mejorar sus mercados de valores y derecho societario, se han elaborado informes de gobierno corporativo con diversas técnicas y alcances, que incluso han superado en algunos aspectos los iniciales. En España, por ejemplo, al Informe Olivencia, hecho público en 1998, le sucedió el Informe Aldama, de 2003. En 2006, en el seno de la Comisión Nacional del Mercado de Valores, CNMV, se constituyó un grupo especial de trabajo para armonizar y actualizar las recomendaciones de los informes Olivencia y Aldama, y elaboró un Código Unificado de Buen Gobierno (CUBG), acompañado de un conjunto de definiciones y recomendaciones complementarias de notable interés. España, Comisión Especial para el Estudio de un Código Ético de los Consejos de Administración de las Sociedades, El gobierno de las sociedades cotizadas, Informe Olivencia (MANUEL Olivencia-Ruiz, dir, Madrid, 26 de febrero de 1998). Disponible en: http://observatoriorsc. org/informe-olivencia/. España, Comisión Especial para el Fomento de la Transparencia y 
línea, el gobierno corporativo constituye un elemento clave para aumentar el crecimiento económico y para fomentar la confianza de los inversores.

Como señalamos precedentemente, hay diferentes modelos de gobierno corporativo. El sistema anglosajón (Estados Unidos y Reino Unido) se caracteriza por empresas de propiedad dispersa o atomizada con accionistas poco involucrados en la gestión, lo que conlleva una estructura con altos niveles de protección a los derechos de los inversionistas minoritarios y un activo mercado de asunción del control. El modelo europeo, en cambio, se caracteriza por empresas de propiedad concentrada, habitualmente familiar o estatal, con propietarios muy involucrados en la gestión empresarial, menores niveles de protección a los accionistas minoritarios y un mercado de tomas de control disminuido. En este contexto, emergen los grupos de empresas que controlan simultáneamente una serie de sociedades de distintos sectores. Ambos modelos presentan problemas de agencia ${ }^{11}$ : en el anglosajón, este se centra en la relación que nace entre la administración de la empresa y sus accionistas, para alinear los intereses de ambos; mientras que en europeo el problema se presenta entre los accionistas mayoritarios y minoritarios, y se persigue evitar que los primeros abusen de su posición en desmedro de los segundos ${ }^{12}$.

Seguridad en los Mercados y Sociedades Cotizadas, Informe Aldama (EnRIQue De Aldama Y Miñón, presidente, 8 de enero de 2003). Disponible en: http://www.cnmv.es/DocPortal/ Publicaciones/CodigoGov/INFORMEFINAL.PDF. España, Comisión Nacional del Mercado de Valores, CNMV, Grupo Especial de Trabajo, Código Unificado de Buen Gobierno, CUBG (Comisión Nacional del Mercado de Valores, CNMV, Madrid mayo de 2006). Disponible en: http://www.cnmv.es/DocPortal/Publicaciones/CodigoGov/Codigo_unificado_Esp_04. pdf. Sobre el particular, Jesús QuiJano-GonzÁLez, Gobierno corporativo. Administración de sociedades mercantiles y responsabilidad, en Gobierno corporativo y responsabilidad social de las empresas, 91-127, 92 (Elena F. Pérez-Carrillo, coord., Marcial Pons, Ediciones Jurídicas y Sociales, Barcelona, 2009).

11 Sobre este término, en 1932, Adolf A. Berle y Gardiner D. Means plantearon la separación entre propiedad y control en las grandes corporaciones estadounidenses. Addolf A. Berle \& Gardiner D. Means, The Modern Corporation and Private Property (MacMillan, New York, 1932). En 1976, Michael C. Jensen y William H. Meckling esbozaron la Agency Theory y los costes de agencia derivados del llamado problema de agencia; este se produce a causa de la diferencia de intereses entre los principales (los propietarios) y sus agentes (los directivos), cuando estos anteponen sus propios intereses a los de aquellos. Michael C. Jensen \& William H. Meckling, Theory of the Firm: Managerial Behavior, Agency Costs and Ownership Structure, 3 Journal of Financial Economics, 4, 305-360, 305-307 (1976). Disponible en: http://www. sciencedirect.com/science/article/pii/0304405X7690026X

12 Sobre este tema, Gonzalo IsLas-RoJas, Gobierno corporativo: teoría económica, principios de la $O C D E$ y la Ley $N^{\circ} 20.382$, en Gobiernos corporativos. Aspectos esenciales de las reformas a su regulación, 9-44 (Javier Wilenmann, coord., Universidad Adolfo Ibáñez, Abeledo Perrot, 
En este orden de ideas, resulta claro que el gobierno corporativo de las sociedades tiene como principal objetivo aminorar los efectos negativos que puede causar sobre la empresa la divergencia de objetivos entre los diversos entes colectivos que confluyen en la sociedad, como accionistas, directorio, gerente, acreedores, clientes y proveedore ${ }^{13}$. La forma de reducir los problemas que causa esta situación (problemas de agencia) es establecer mecanismos que directa o indirectamente disminuyan sus efectos. El primer instrumento para hacerlo es el propio contrato que fija las obligaciones de los socios de manera detallada; el segundo es la normativa, con el objeto de alinear los intereses u objetivos de los sujetos intervinientes en la relación y la reducción de las asimetrías informativas en aras de favorecer la inversión, el financiamiento de la empresa, sus relaciones comerciales y su imagen corporativa.

Si bien los PBGC se centran en los problemas de la separación entre propiedad y control ${ }^{14}$, no podemos afirmar que se trata de una cuestión exclusivamente circunscrita a las relaciones entre los accionistas y el cuerpo directivo, aunque de hecho sean el elemento central. Este abarca una serie de relaciones entre el cuerpo directivo de una empresa, su consejo, sus accionistas y otras partes intere-

Thomson Reuters, Santiago, 2011)

13 José Luis Crespo-Espert, Fernando Crecente-Romero \& Carlos Mir-Fernández, Gobierno corporativo de las sociedades no cotizadas desde la perspectiva de la economía financiera, en Gobierno corporativo en sociedades no cotizadas, 247-324, 247-318 (SANtiago Hierro-Anibarro, dir., Marcial Pons, Ediciones Jurídicas y Sociales, Madrid, Barcelona, Buenos Aires, São Paulo, 2014)

14 En general, el gobierno corporativo se ve afectado por las relaciones entre los agentes que intervienen en el sistema de gobierno corporativo, como los accionistas con poder de control, que pueden ser personas aisladas, sociedades familiares, alianzas en bloque $u$ otras sociedades que actúan por medio de un grupo de empresas o de participaciones cruzadas, que influyen significativamente en el comportamiento de la sociedad. Por otra parte, los accionistas individuales si bien no pretenden ejercitar derechos de gobierno, sí les preocupa la posibilidad de no obtener un trato justo por parte de los accionistas con poder de control y el cuerpo directivo. Adicionalmente, los acreedores juegan un papel destacado en diversos sistemas de gobierno, y pueden servir como agentes supervisores de los resultados de la sociedad. Los empleados y otras partes interesadas también desempeñan una función importante a la hora de contribuir al éxito de la sociedad a largo plazo y a sus resultados, mientras los gobiernos establecen el marco general institucional y legal en materia de gobierno corporativo. El papel de cada uno de estos participantes y la interacción entre ellos varían enormemente en función del país de la OCDE en que desarrollen su actividad; lo mismo ocurre en los países no pertenecientes a esta organización. Estas relaciones están sujetas, en parte, a las leyes y reglamentos, pero también a la adaptación voluntaria y, más importante, a las fuerzas del mercado. Organización para la Cooperación y el Desarrollo Económicos, OCDE, Principios de gobierno corporativo (Organización para la Cooperación y el Desarrollo Económicos, OCDE, París, 2004). Disponible en: http://www.oecd.org/daf/ca/corporategovernance principles/37191543.pdf 
sadas (stakeholders). Su relevancia se percibe en el establecimiento de una estructura que permite planificar y alcanzar los objetivos de la empresa, y determinar los medios que pueden utilizarse para alcanzarlos. En esta línea, un buen gobierno corporativo debe ofrecer incentivos apropiados al cuerpo directivo a fin de que se realicen los intereses de la sociedad; al mismo tiempo, la existencia de un sistema eficiente de gobierno contribuye a generar el grado de confianza necesario para el correcto funcionamiento de una economía de mercado ${ }^{15}$; por otro lado, los PBGC regulan los procesos de toma de decisión en una sociedad, asumiendo su impacto en diferentes ámbitos ${ }^{16}$. En definitiva, un buen gobierno corporativo resuelve ciertos problemas relativos a la equidad entre accionistas; las relaciones de agencia; disminuye las asimetrías de información; disminuye los costos de transacción de las decisiones colectivas; $y$ representa mejor las distintas partes interesadas.

La naturaleza de los PBGC es evolutiva, razón por la cual deben ser permanentemente revisados de acuerdo a los cambios que se produzcan en el entorno ${ }^{17}$. En otras palabras, las sociedades, para seguir siendo competitivas en un mundo sujeto a continuas modificaciones, deben ser innovadoras y adaptar sus prácticas de

15 En la actualidad, la regulación de los gobiernos corporativos tiene relación con los sistemas de deberes establecidos en las legislaciones societarias, en las cuales el régimen de responsabilidad normalmente se estructura sobre la base de la severidad contra el fraude y la negligencia. En este sentido, CÁndido PAZ-Ares, Deberes fiduciarios y responsabilidad de los administradores (reflexiones sobre la reforma legal en Latinoamérica) (Organisation for Economic Co-operation and Development, OECD, in co-operation with the World Bank Group, The Third Meeting of the Latin American Corporate Governance Roundtable, Mexico, 8-10 April 2002). Disponible en: http://www.oecd.org/corporate/ca/corporategovernanceprinciples/2576714.pdf

16 Entre las que figuran las Lineas directrices de la OCDE para empresas multinacionales y la Convención de Lucha para combatir el cohecho de servidores públicos extranjeros en transacciones comerciales internacionales y por otras organizaciones internacionales. En tal sentido, hoy cualquier Estado que pretenda incorporarse al selecto grupo de la Organización para la Cooperación y el Desarrollo Económicos (OCDE), necesariamente debe atender y seguir sus orientaciones y observar sus exigencias en sus diferentes ámbitos. Organización para la Cooperación y el Desarrollo Económicos, OCDE, Líneas directrices de la OCDE para empresas multinacionales (Organisation for Economic Co-operation and Development, OECD, OECD Publishing, Paris, 1976, 2011). Disponible en: http://www.oecd.org/daf/inv/ mne/48004323.pdf, http://mneguidelines.oecd.org/text/, http://www.oecd.org/daf/inv/mne/ MNEguidelinesESPANOL.pdf. Organización para la Cooperación y el Desarrollo Económicos, OCDE, Convención para combatir el cohecho de servidores públicos extranjeros en transacciones comerciales internacionales y documentos relacionados, adoptada por la Conferencia Negociadora, París, 21 de noviembre de 1997. Disponible en: https://www.oecd. org/daf/anti-bribery/ConvCombatBribery_Spanish.pdf

17 A este respecto, destaca el Foro Global de Gobierno Corporativo (Global Corporate Governance Forum, GCGF), fundado en 1999 por el Banco Mundial y la OCDE. 
gobierno corporativo de forma que sean capaces de atender nuevas demandas y aprovechar otras oportunidades. De manera similar, los Estados deben tomar conciencia de que sobre ellos recae la responsabilidad de crear un marco normativo que proporcione la suficiente flexibilidad a la empresa en aras de permitir que los mercados funcionen eficazmente y sean capaces de satisfacer las expectativas de los accionistas y otras partes interesadas.

Finalmente, precisamos que, a pesar de que los principios no tienen fuerza vinculante, estos han tenido éxito dado que las reglas de conducta que contienen son consideradas como mejores prácticas. Ellas han servido como modelo legislativo ${ }^{18}$, y han contribuido, de este modo, al proceso de modernización y armonización del derecho societario por vía legislativa y/o convencional ${ }^{19}$.

\title{
II. SOBRE LA EXTENSIÓN DE LOS PRINCIPIOS DE BUEN GOBIERNO CORPORATIVO EN LAS SOCIEDADES NO COTIZADAS
}

\begin{abstract}
¿Es posible extender los principios de buen gobierno corporativo a las sociedades no cotizadas? La respuesta es indudablemente afirmativa. Como señalamos, si bien estos principios nacen con la vocación de regular las sociedades que cotizan en el mercado de valores, pues este tipo presenta normalmente los mayores problemas de agencia y de información ya mencionados, nada impide que
\end{abstract}

18 En Chile, para la Superintendencia de Valores y Seguros, SVS, el gobierno corporativo, en un concepto amplio, es un sistema a través del cual un asegurador se gobierna a sí mismo. Esto incluye entre otros: a. La cultura corporativa (valores, ética, facilidad con que los empleados comunican inquietudes o informan irregularidades, etc.); b. La estructura corporativa (directorio, alta gerencia, funciones del área de negocios, etc.); c. Las políticas y documentación esencial de gobernabilidad interna (estatutos, reglas organizacionales, códigos de conducta, mandatos de los comités, etc.); d. La estrategia, políticas, procedimientos de control interno y gestión de riesgos, y e. El proceso de toma de decisiones y acciones ligadas a los conceptos previamente señalados. Chile, Superintendencia de Valores y Seguros, SVS, Norma de Carácter General 309, NCG 309, Principios de gobierno corporativo y sistemas de gestión de riesgo y control interno, 20 de junio de 2011. Disponible en: http://www.svs.cl/institucional/ mercados/ver_archivo.php?archivo=/web/compendio/ncg/ncg_309_2011.pdf

19 Desde la aprobación de los Principios en 1999, estos han constituido la base de las iniciativas en el ámbito del gobierno corporativo puestas en práctica tanto en los países de la OCDE como en los países no miembros. Por su parte, el Foro sobre Estabilidad Financiera los ha adoptado como una de las doce normas fundamentales para garantizar unos sistemas financieros sanos y, por consiguiente, constituyen también la base del componente de gobierno corporativo de los Informes sobre la Observancia de Códigos y Normas (Reports on the Observance of Standards and Codes, ROSCs) del Banco Mundial/Fondo Monetario Internacional, FMI. https://www.worldbank.org/ifa/rosc.html 
estos se puedan extender a las sociedades no cotizadas. Con todo, si profundizamos en esta materia, surgen nuevas interrogantes: ¿qué entendemos por sociedades no cotizadas?, ¿cuáles serían los efectos positivos de esta extensión?, ¿cuáles serían los requisitos para poder extrapolar su aplicación a este tipo societario?, ¿resulta conveniente realizar esta extensión a todas las sociedades que no cotizan en el mercado de valores? A continuación, nos referiremos a estos puntos.

\section{A. Sociedad no cotizada}

No hay una definición de sociedades no cotizadas. La delimitación de estas sociedades es residual, pues lo son todas aquellas sociedades que no cotizan en el mercado de valores. De este modo, y dado que la delimitación de este tipo societario se construye dogmáticamente por vía de la exclusión, hemos necesariamente de detenernos en los principales rasgos de estas últimas.

Desde una perspectiva amplia, las sociedades cotizadas son sociedades anónimas cuyas acciones han de estar admitidas a negociación en un mercado secundario oficial de valores y ellas normalmente integran las grandes corporaciones empresariales de los sectores financieros, energéticos, alimentarios, entre otros, cuyas necesidades de financiamiento solo pueden satisfacerse acudiendo al mercado de valores. La sociedad cotizada se descompone en tres elementos básicos: a) Unos sujetos, que son las sociedades cuyo capital está dividido en acciones e integrado por las aportaciones de los socios, que no responderán personalmente de las deudas sociales; b) Unos objetos, denominados acciones, que corresponden a un tipo de valor negociable y que pertenecen a la categoría de los instrumentos financieros que quedan comprendidos en el ámbito de aplicación de la Ley de Mercado de Valores; y c) Una situación concreta de funcionamiento, que consiste en que estas acciones deben estar admitidas a negociación en un mercado oficial de valores por las entidades que corresponda.

Entre los rasgos característicos de esta clase de sociedades y de su régimen legal, destacan dos: por un lado, la imposición de deberes específicos a sus administradores y el reconocimiento de ciertos derechos a los accionistas e inversores que adquieren los valores que ellas emiten; $y$, por otro, la transparencia contable, 
financiera ${ }^{20}$ y política que la ley les impone ${ }^{21}$. El fundamento es fácilmente comprensible, pues si consideramos que las sociedades cotizadas comprometen el ahorro de miles de pequeños y medianos inversores en la negociación de los valores que emiten, es justo que ofrezcan al mercado un nivel adecuado de transparencia y control. Sobre esta base, se les somete a unas obligaciones típicas en cuanto a la información financiera que deben proveer y de estructura de poder político, junto con establecer la imposibilidad de restricciones estatutarias a la libre transmisibilidad de sus acciones.

Desde esta óptica, la justificación de la aplicación de los principios de gobierno corporativo a las sociedades cotizadas reside en los problemas de agencia que se presentan en ellas de manera frecuente $\mathrm{y}$, muy especialmente, en el conflicto que genera la separación entre la propiedad y el control en la sociedad anónima abierta ${ }^{22}$. Por otra parte, la observancia de estos principios está vinculada con el sistema de financiamiento de esta clase de sociedades, de modo que la efectiva adopción de las recomendaciones del buen gobierno resulta esencial en la percepción de los mercados bursátiles ${ }^{23}$.

De lo expresado, estamos en condiciones de afirmar que la sociedad no cotizada se caracteriza por comprender una amplia y variada tipología societaria y empresarial, que solo excluye a las sociedades anónimas cuyas acciones estén admitidas a cotización en un mercado secundario oficial de valores. Estas son sociedades poseen estructuras, tamaños y complejidades muy dispares entre

20 Carlos Enrique Kitagawa, Maisa de Souza Ribeiro \& Paula Carolina Ciampaglia-Nardi, The Responsibilities of the Board: The Level of Compliance of Latin Americans' Companies to the OECD principles of Corporate Governance, 9 Research in Accounting in Emerging Economies, 97-117 (2009). Fernando Lefort \& Francisco Urzúa, Board Independence Firm Performance and Ownership Concentration: Evidence from Chile, 61 Journal of Business Research, 615-622 (2008). Disponible en: http://papers.ssrn.com/sol3/papers.cfm?abstract_id=1664074

21 Sobre el tema, Alberto Javier Tapia-Hermida, Las sociedades cotizadas: noción y estatuto jurídico, 2 (Universidad Complutense de Madrid, Departamento de Derecho Mercantil, Facultad de Derecho, Documento de Trabajo 26, Madrid, 2010). Disponible en: http://eprints. ucm.es/9896/1/A.J._Tapia._Sociedades_Cotizadas.pdf

22 Fernando Sánchez-Calero, Los administradores en las sociedades de capital, 738-743 (Thomson Civitas, Madrid, 2005). José María Garrido, La distribución y el control del poder en las sociedades cotizadas y los inversores institucionales, 37, 77-106 (Publicaciones Real Colegio de España en Bolonia, Zaragoza, 2002).

23 Organisation for Economic Co-operation and Development, OECD, Corporate Governance of Non-Listed Companies in Emerging Markets, 8 (Organisation for Economic Co-operation and Development, OECD, Paris, 2006). Disponible en: http://www.oecd.org/daf/ca/corporate governanceprinciples/corporategovernanceofnon-listedcompaniesinemergingmarkets.htm. Joseph A. McCahery \& Erik P. M. Vermeulen, Corporate Governance of Non-Listed Companies, 7 (Oxford University Press, OUP, Oxford, 2008). 
sí, de manera que a priori no es posible sostener un grado de uniformidad entre ellas.

\section{B. ¿Por qué y cómo extender los PBGC a las sociedades no cotizadas? Fundamentos e instrumentos}

\section{Justificación de la extensión de los PBGC a la sociedad no cotizada}

Entre los motivos que explican la adopción voluntaria de normas de gobierno corporativo por parte de sociedades no cotizadas, está la búsqueda alternativa de financiamiento para las sociedades, tras la dirección que ha tomado el sistema del crédito bancario representado por el private equity y los hedge funds, por citar inversores especialmente interesados y activos en el desarrollo de fórmulas de gobierno corporativo para las sociedades bajo su gestión. En otros casos, ello resulta de la imposición que ejercen las empresas multinacionales a sus socios locales cuando se emplean formas de colaboración empresarial como la sociedad conjunta (joint venture) o modelos de asociación consorcial. Precisamente, la internacionalización de las relaciones y de los flujos financieros y comerciales que constituyen una oportunidad para la empresa, ha destacado la utilidad de los estándares de buen gobierno para generar confianza en inversores, proveedores, clientes y entidades financieras en un entorno cada vez más global, lo que, en última instancia, serviría a la sociedad que aplica voluntariamente los PBGC para mejorar sus expectativas de crecimiento y favorecer su competitividad ${ }^{24}$.

Otro fundamento para extender estos principios a estas sociedades se refiere a la organización y el funcionamiento de sus órganos, que se reflejan en la creación y el fortalecimiento de las estructuras de gestión y una conducta de sus administradores tendiente a asegurar la expansión y continuidad del negocio a largo plazo, lo que privilegia el interés social. Su adopción puede traducirse en una

24 Anja Hucke \& Susan Just, Die Anwendbarkeit des DCGK auf nicht börsennotierte Unternehmen Welche Standards sollten Sekundäradressaten übernehmen?, 2 Zeitschrift für Corporate Governance: ZCG; Leitung und Überwachung in der Unternehmens- und Prüfungspraxis, 5-12, 11 (2007). 
inmediata mejora en el funcionamiento de sus órganos sociales al hacerlos más eficientes ${ }^{25}$; así, en el caso de la administración de la sociedad, las normas de buen gobierno contribuyen decididamente a profesionalizar la gestión de estas sociedades, algo de lo que frecuentemente carecen las pequeñas y medianas empresas, y que resulta indispensable para su desarrollo en todas sus dimensiones. Otro aspecto relevante consiste en contar con mejores herramientas para reducir los conflictos intrasocietarios, especialmente intensos en el ámbito de las empresas familiares.

Como vemos, los fundamentos no coinciden con la instauración de estos principios en las sociedades cotizadas. En estas, la atención se centra en la asimetría de los intereses que confluyen en la empresa, toda vez que los directivos tienden a priorizar los suyos $^{26}$ o sus decisiones responden al interés de los accionistas mayoritarios que tienen potestad sobre su nombramiento, retribución o destitución o, incluso, porque entienden que otros interesados o stakeholders externos tienen intereses que la administración societaria debe tomar en consideración ${ }^{27}$ (problemas de agencia); en las sociedades no cotizadas, en cambio, es habitual encontrar entidades controladas por un solo individuo o por unos pocos que corresponden a personas vinculadas, de manera que los problemas antes descritos normalmente no se presentan, pues sus administradores son normalmente socios de la sociedad ${ }^{28}$; en estas últimas, el gobierno corporativo exige enfrentar problemas específicos, como

25 La literatura económica sistemáticamente ha considerado positiva la relación entre las buenas prácticas de gobierno corporativo y un mejor desempeño de la empresa, tanto general en el financiamiento de mercado de valores, como individual respecto de los resultados de las empresas. Las líneas de investigación más recientes intentan identificar en forma precisa cuáles son los mecanismos más relevantes en esta obtención, al determinar los aspectos legales o las prácticas de gobierno corporativo que permiten explicar este desempeño. Marco Pagano \& Paolo F. Volpin, The Political Economy of Corporate Governance, 95 The American Economic Review, 1005-1030 (2005).

26 Adolf A. Berle \& Gardiner D. Means, The Modern Corporation and Private Property (MacMillan, New York, 1932).

27 Silvia Gómez-Ansón, Carlos Fernández \& Ana Isabel Fernández-Álvarez, El papel supervisor del consejo de administración sobre la actuación gerencial. Evidencia para el caso español, 22 Investigaciones Económicas, 501-516 (1998).

28 En estos casos, parece más razonable considerar una teoría alternativa, la "Stewardship Theory" (Teoría del Servidor o del Administrador Leal). Se considera en esta teoría que los administradores y los directivos no anteponen sus intereses a los de los socios o a los de la sociedad y que actúan con la diligencia debida en la defensa del interés social y la salvaguarda de los activos de la empresa. No es fácil pensar que en este tipo de empresas, particularmente si son familiares, los altos directivos y los administradores puedan mantenerse en sus puestos si actúan en contra de los intereses de la mayoría de los socios. 
la delegación de autoridad, la profesionalización de la gestión, la adecuada adopción de decisiones, la prevención y solución eficiente de conflictos, la integración de los posibles intereses divergentes de los socios o accionistas, la atracción de capitales —más allá de los aportes de los fundadores_-, la mitigación de los riesgos de iliquidez presentes en la mayoría de las entidades cerradas (consecuencia directa de que no participan en mercados públicos), y la mantención del prestigio de entidades de reducidas dimensiones o muy dependientes del prestigio en sus comunidades locales ${ }^{29}$.

Siguiendo este orden de ideas, los principales objetivos de esta extensión se reducen a dos: administrativo y financiero. En relación con el primero, debemos subrayar que la resolución del problema de la alineación y la divergencia de intereses en las empresas de menor dimensión, presta atención al efecto que tiene en la toma de decisiones la mayor especialización de la empresa, la participación de los accionistas en la dirección y los estrechos vínculos existentes entre la dirección, los trabajadores, los clientes y los proveedores. En esta línea, cuanto menor sea el tamaño de la sociedad, mayor debe ser el grado de especialización para soportar la competitividad. La contrapartida de los efectos económicos que esto tiene en la empresa es la mayor retribución que deben recibir directivos y trabajadores y, al mismo tiempo, la exigencia de una mayor rentabilidad financiera por quienes aportan el capital; la consecución de estos objetivos se traduce en un mayor compromiso entre la empresa y los trabajadores, lo que permite a estos últimos una mayor permanencia en el empleo. Así mismo, el control hacia los directivos facilita la adecuada gestión de las sociedades, lo que privilegia los intereses de estas últimas.

Respecto del segundo objetivo, el financiero, partimos de la base de que estas sociedades normalmente tienen menor capacidad financiera que las cotizadas, debido a que no pueden acceder a un mercado financiero con un bajo costo, lo que repercute en la toma de decisiones y la rigidez de la inversión realizada. En efecto, la cuantía de fondos propios de que disponen estas sociedades está sujeta a una serie de restricciones y el capital con que cuentan está

29 European Confederation of Director's Associations, ecoDa, Corporate Governance Guidance and Principles for Unlisted Companies in Europe (ecoDa, Brussels, 2010). Disponible en: http:// ecoda.org/uploads/media/GUIDANCE_-_2010_CG_for_Unlisted_-_EU.pdf 
limitado por el número de sus socios y sus patrimonios personales, de manera que la obtención de financiamiento externo depende en buena medida de dar mayores garantías a los acreedores, lo que redunda en la confianza que estas empresas logran transmitir en su entorno, de manera que la adopción de un buen gobierno contribuye a la generación de confianza, la disminución de riesgos $\mathrm{y}$ el incremento de fuentes alternativas de financiamiento, lo que favorece no solo su independencia sino también su crecimiento.

En resumen, si bien en principio no puede darse una respuesta general para todos los tipos societarios que no cotizan en mercado de valores, podemos concluir que la justificación de la aplicación de principios de buen gobierno a estas sociedades difiere de aquella que concurre para las cotizadas. Las razones que lo justifican para las primeras se vinculan con la reducción de los costos, la mejora de acceso a fuentes de financiación, de sus expectativas de crecimiento y de desarrollo nacional e internacional; mientras que para las segundas, ello se conecta con un mejoramiento en su gestión interna y el incremento de fuentes de financiamiento.

\section{2. Ámbito subjetivo de aplicación, principios aplicables e instrumentos idóneos}

Todo parece indicar que la aplicación de estos principios exige un cierto tamaño en las destinatarias y un cierto contexto, pero no parece justificarse para las iniciativas empresariales más modestas por los costos que ello implica ${ }^{30}$. De forma general, es posible observar que para la aplicación se debe prescindir de la naturaleza jurídica de los distintos tipos de sociedad no cotizada, atendiendo más bien a criterios cuantitativos y cualitativos. Con relación a los

30 En Europa, la extensión de los principios de buen gobierno a las pequeñas y medianas empresas enfrenta su primera dificultad en la definición de pequeña y mediana empresa, pyme, a la que le sigue la falta de adecuación de las recomendaciones de buen gobierno de la sociedad cotizada para iniciativas empresariales de poca dimensión. Suele adoptarse el concepto comunitario de pyme que se recoge en la Recomendación 2003/361/CE de la Comisión Europea, sobre la definición de microempresas, pequeñas y medianas empresas. Se trata de un concepto amplio de pequeña y mediana empresa que no se vincula a ningún tipo societario específico ni siquiera a la forma social, ya que pueden considerarse incluidos en él tanto las personas jurídicas como los empresarios individuales. Comisión de las Comunidades Europeas, Recomendación 2003/361/CE de la Comisión, 6 de mayo de 2003, sobre la definición de microempresas, pequeñas y medianas empresas, L 124/36 Diario Oficial de la Unión Europea, 20 de mayo de 2003. Disponible en: http://eur-lex.europa.eu/legal-content/ $\mathrm{ES} / \mathrm{TXT} /$ uri $=$ celex $\% 3 \mathrm{~A} 52003 \mathrm{DC} 0284$ 
primeros, numerosos principios de buen gobierno corporativo están orientados específicamente a la pequeña y mediana empresa, en los que se impone la dimensión de la sociedad como criterio rector; respecto a los segundos, el más común de estos criterios refiere tanto a la propiedad como a la gestión de empresa concernida. De este modo, no todas las recomendaciones de buen gobierno resultarían aplicables a las sociedades no cotizadas, sino solo aquellas que resulten pertinentes y eficaces de acuerdo a los criterios antes descritos. En otras palabras, para decidir esta cuestión se debe valorar, y en su caso descartar, su aplicación en función del tamaño de la sociedad, las necesidades y la madurez del negocio y la estructura de la propiedad.

En relación con los instrumentos, debemos considerar que la disparidad de regímenes jurídicos y las particularidades de las distintas fases de evolución de una iniciativa empresarial — desde sus inicios hasta su expansión-impiden formular recomendaciones con validez general para las sociedades no cotizadas. Los instrumentos jurídicos de organización de la propiedad y el control de la empresa son diversos: van desde el contrato social y las previsiones estatutarias, hasta los pactos privados y los reglamentos orgánicos internos. De este modo, el éxito de la extensión de los PBGC a estas sociedades dependerá, en buena medida, de sus características, del contexto en que desarrollan su actividad, y del grado de flexibilidad del régimen jurídico que les sea aplicable en cada ordenamiento ${ }^{31}$.

\section{Aplicación de los PBGC a la sociedad no cotizada}

Ligado a lo anterior, en la aplicación o adopción de los principios de buen gobierno corporativo en las sociedades no cotizadas, podemos distinguir al menos tres posibilidades de aplicación, dependiendo del instrumento jurídico destinado a dar forma ${ }^{32}$. En un primer nivel se sitúan las normas jurídicas que pueda dictar un determinado país, cuya observancia será normalmente obligatoria debido a su carácter imperativo; en el segundo, están las de origen

31 Andrei Shleifer \& Robert W. Vishny, A Survey of Corporate Governance, 52 Journal of Finance, 2, 737-783 (1997). Disponible en: http://scholar.harvard.edu/files/shleifer/files/surveycorpgov.pdf

32 Santiago Hierro-Anibarro \& Marta Zabaleta-Díaz, Buen gobierno corporativo de la pyme y de la empresa familiar en la Unión Europea, en Gobierno corporativo en sociedades no cotizadas, 39-78 (Marcial Pons, Madrid, Barcelona, Buenos Aires, São Paulo, 2014). 
contractual que las partes incorporan a los estatutos sociales en el ejercicio de su libertad contractual; por último, en un tercer nivel, figura la adhesión voluntaria a las recomendaciones por parte de los $\operatorname{socios}^{33}$. En este último nivel, nos referimos a la autorregulación que efectúa la propia sociedad por medio de códigos o informes ${ }^{34}$; la ventaja de este instrumento se traduce en su flexibilidad, al permitir a las empresas adaptar sus prácticas de gobierno a situaciones específicas tomando en consideración su tamaño, la estructura de su propiedad y las particularidades sectoriales ${ }^{35}$. Además, los códigos de buen gobierno promueven la adopción de procesos internos y externos de control de riesgos y de los gestores de la sociedad, esto ocurre pues la autorregulación representa un estándar de buena organización y gestión bien considerado por el público.

\section{LA PROMOCIÓN DEL BUEN GOBIERNO CORPORATIVO A LAS SOCIEDADES NO COTIZADAS EN EUROPA}

En las dos últimas décadas, después de años de dedicación prácticamente exclusiva a la gran empresa, la Comisión Europea ha vuelto su mirada a la sociedad no cotizada y se ha interesado en la simplificación del proceso de constitución destinado a facilitar la creación de nuevas empresas ${ }^{36} \mathrm{y}$, más recientemente, por el go-

33 Por ejemplo, Corporación Andina de Fomento, CAF, Manual de Gobierno Corporativo para empresas de capital cerrado (Corporación Andina de Fomento, CAF, Caracas, 2010). Disponible en: http://publicaciones.caf.com/media/25371/gc_capital_cerrado_2.pdf. Colombia, Superintendencia de Sociedades, Cámara de Comercio de Bogotá \& Confecámaras, Guía colombiana sobre gobierno corporativo para sociedades cerradas y de familia (Superintendencia de Sociedades, Cámara de Comercio de Bogotá \& Confecámaras, Bogotá, septiembre de 2009). Disponible en: http://www.supersociedades.gov.co/inspeccion-vigilancia-y-control/gobiernocorporativo-y-rse/cartillas-y-guias/Cartillas $\% 20 \mathrm{y} \% 20$ Guias/guia $\% 20$ colombiana $\% 20 \mathrm{de} \% 20$ gobierno $\% 20$ corporativo $\% 20(8)$.pdf

34 Luca Enriques, Henry Hansmann \& Reinier Kraakman, The Basic Governance Structure: The Interest of Shareholders as a Class, en The Anatomy of Corporate Law. A Comparative and Functional Approach, 67 ( $2^{\text {nd }}$ ed., Reinier Kraakman, John Armour, Paul Davies, Luca Enriques, Henry B. Hansmann, Gérard Hertig, Klaus J. Hopt, Hideki Kanda \& Edward B. Rock, Oxford University Press, OUP, Oxford, 2010).

35 Comisión Europea, $\mathrm{COM(2011)} 164$ final, Libro Verde. La normativa de gobierno corporativo de la Unión Europea, 20-21 (Comisión Europea, Bruselas, 2011). Disponible en: http://ec.europa. eu/internal_market/company/docs/modern/com2011-164_es.pdf, http://ec.europa.eu/internal_ market/company/docs/modern/com2011-164_en.pdf

36 Santiago Hierro-Anibarro, La politica comunitaria de simplificación del derecho de sociedades, en Simplificar el derecho de sociedades, 65-109 (Santiago Hierro-Anibarro, dir., Marcial Pons, Ediciones Jurídicas y Sociales, Madrid, Barcelona, Buenos Aires, São Paulo, 2010). 
bierno corporativo de estas empresas ${ }^{37}$. Este cambio ha coincidido con el impulso que la Unión Europea ha dado a los gobiernos corporativos, de ahí que en la actualidad la totalidad de los Estados miembros los haya incorporado directamente a sus ordenamientos o sin una modificación legal sirvan de complemento al régimen legal societario. El gobierno corporativo reclamó una mayor regulación ${ }^{38}$ desde 2003, cuando se incluyó este tema en la agenda de la Comisión Europea con la publicación del Plan de acción para la modernización del derecho de sociedades y mejora del gobierno corporativo en la Unión Europea ${ }^{39}$.

En esta dirección, desde hace ya algún tiempo, diversas instituciones nacionales e internacionales vienen elaborando documentos y códigos de buen gobierno corporativo tanto para sociedades cotizadas como no cotizadas. Estos instrumentos tienen un carácter estrictamente voluntario y se ofrecen como una herramienta útil para aquellas empresas que aspiran a incrementar su crecimiento y expansión, al profesionalizar su gestión, lo que representa uno de los principales incentivos para la adopción de los principios de buen gobierno por parte de las sociedades no cotizadas ${ }^{40}$.

Con todo, la falta de asunción voluntaria de las recomendaciones y los escándalos financieros ocurridos hace algunos años provo-

37 Comisión Europea, $\operatorname{COM(2011)~} 164$ final, Libro Verde. La normativa de gobierno corporativo de la Unión Europea, 4-5 (Comisión Europea, Bruselas, 2011). Disponible en: http://ec.europa. eu/internal_market/company/docs/modern/com2011-164_es.pdf, http://ec.europa.eu/internal_ market/company/docs/modern/com2011-164_en.pdf

38 MARTA ZABALETA-Díaz, La experiencia comparada de gobierno corporativo en sociedad no cotizada, en Gobierno corporativo en sociedades no cotizadas, 83-144 (SANtiago Hierro-Anibarro, dir., Marcial Pons, Ediciones Jurídicas y Sociales, Madrid, Barcelona, Buenos Aires, São Paulo, 2014).

39 Comisión de las Comunidades Europeas, COM (2003) 284 final, 21 de mayo de 2003, Comunicación de la Comisión al Consejo y al Parlamento Europeo, Modernización del Derecho de sociedades y mejora de la gobernanza empresarial en la Unión Europea. Un plan para avanzar (Comisión Europea, 2003). Disponible en: http://ec.europa.eu/transparency/regdoc/?fuseaction= list $\&$ coteId $=1 \&$ year $=2003 \&$ number $=284 \&$ language $=$ es

40 Este interés también se advierte en el ámbito latinoamericano. En efecto, numerosas naciones emergentes americanas han propiciado la extensión de los códigos de gobierno inicialmente diseñados para las sociedades cotizadas a aquellas que no lo son, como México, Perú y Brasil, o han adoptado directamente un código específico para las sociedades no cotizadas, como ha sucedido con el relativo a la pyme y la empresa familiar, elaborado por la Corporación Andina de Fomento y de vocación supranacional para toda Latinoamérica, o bien ha correspondido a iniciativas de naturaleza estatal, como ha sucedido en Colombia, e idéntico patrón puede observarse en diferentes países asiáticos y africanos. SAntiago Hierro-Anibarro, Gobierno corporativo sin mercado de valores, en Gobierno corporativo en sociedades no cotizadas, 17-33, 18 ss. (Santiago Hierro-Anibarro, dir., Marcial Pons, Ediciones Jurídicas y Sociales, Madrid, Barcelona, Buenos Aires, São Paulo, 2014). 
caron una mayor intervención legislativa en estas materias, de tal forma que algunas de las recomendaciones de buen gobierno se transformaron en normas imperativas. Se transita, de este modo, de un modelo basado exclusivamente en la autorregulación ${ }^{41}$ y la adopción voluntaria de los principios de buen gobierno, a otro que combina recomendaciones de carácter voluntario con normas imperativas. El foco se ha puesto principalmente en las entidades financieras $y$, en particular, en las graves carencias en materia de gestión de riesgos, aunque también en la falta de capacitación de los directivos de estas entidades y sus perversos sistemas de retribución orientados a rendimientos a corto plazo.

En esta línea de pensamiento, en junio de 2010, la Comisión Europea sometió a consulta pública el Libro Verde. El gobierno corporativo en las entidades financieras y las políticas de remuneración ${ }^{42}$, que proponía un conjunto de medidas destinadas a mejorar el funcionamiento y la composición de los consejos de administración, fomentar la participación de los accionistas, las autoridades de supervisión y los auditores, y reorientar las políticas de remuneración y evitar la adopción de riesgos excesivos. Unos meses más tarde, se publicó el Libro Verde, Política de auditoría: lecciones de la crisis ${ }^{43}$. Finalmente, el 5 de abril de 2011, la Comisión sometió a consulta pública el documento Libro Verde. La normativa de gobierno corporativo de la Unión Europea ${ }^{44}$, sobre el gobierno de las sociedades cotizadas en general, que aborda cuestiones centrales de gobierno corporativo, como el consejo de administración, la remuneración de los administradores, la abstención generalizada por parte de los

41 La crisis financiera desencadenada a finales de 2007 ha cuestionado las virtudes de la autorregulación hasta el punto de señalar las deficiencias prácticas de buen gobierno como una de las causas de la crisis. Sobre este tema, IAIN MACNeIL, The Trajectory of Regulatory Reform in the UK in the Wake of the Financial Crisis, 11 European Business Organization Law Review, EBOR, 4, 483-526 (2010). Disponible en: http://eprints.gla.ac.uk/41807/1/41807.pdf

42 Comisión Europea, $\operatorname{COM}(2010) 284$ final, Libro Verde. El gobierno corporativo en las entidades financieras y las políticas de remuneración (Comisión Europea, Bruselas, 2 de junio de 2010). Disponible en: http://eur-lex.europa.eu/LexUriServ/LexUriServ. do?uri=COM:2010:0284:FIN:ES:PDF

43 Comisión Europea, $\operatorname{COM}(2010) 561$ final, Libro Verde, Política de auditoría: lecciones de la crisis (Comisión Europea, Bruselas, 13 de octubre de 2010). Disponible en: https://publications. europa.eu/es/publication-detail/-/publication/08744053-2f56-415a-a985-7ceaef3d3b3a/ language-es

44 Comisión Europea, $\operatorname{COM(2011)~} 164$ final, Libro Verde. La normativa de gobierno corporativo de la Unión Europea (Comisión Europea, Bruselas, 2011). Disponible en: http://ec.europa.eu/ internal_market/company/docs/modern/com2011-164_es.pdf, http://ec.europa.eu/internal_ market/company/docs/modern/com2011-164_en.pdf 
accionistas en la toma de decisiones y la aplicación del principio de comply or explain.

Una de las preguntas que planteaba la Comisión era si se debían adoptar medidas de gobierno corporativo en el ámbito comunitario para las empresas no cotizadas y si la Unión Europea se debía centrar en promover la elaboración y aplicación de códigos voluntarios para estas sociedades. La respuesta fue mayoritariamente negativa, el $70 \%$ consideró que no resultaba necesaria ninguna iniciativa comunitaria, con el argumento de que el núcleo de las recomendaciones de buen gobierno no era adecuado ni resultaba extrapolable a las sociedades no cotizadas, en la medida en que en estas no se dan los problemas de agencia que las recomendaciones de buen gobierno pretenden corregir. El rechazo de un gobierno corporativo para las sociedades cerradas viene en parte determinado por un contexto general de escepticismo respecto de la eficacia y utilidad de las recomendaciones de buen gobierno y la demanda de mayor flexibilidad y autonomía privada. Las razones de esta desconfianza tienen una estrecha relación con el papel que se atribuye a las malas prácticas de las entidades de crédito en la crisis financiera ${ }^{45}$. Desde este sitial, no resulta extraño que las iniciativas de gobierno corporativo anunciadas por la Comisión Europea en este nuevo Plan de Acción no hayan despertado mayor entusiasmo para las sociedades no cotizadas.

Más allá de la situación general descrita, es preciso considerar que hay códigos particulares de buen gobierno que no limitan su ámbito de aplicación a las sociedades cotizadas, dado que también recomiendan su seguimiento a las empresas que no tengan tal condición. Este es el caso del Código alemán de gobierno corporativo

45 Uno de los motivos que desincentivaron su aplicación fue el hecho de que no había datos fiables que acreditasen el seguimiento y la aplicación efectiva de las recomendaciones de buen gobierno. Se criticó el formalismo en que parece haberse convertido el informe de gobierno, según se desprende del Estudio sobre prácticas de supervisión y aplicación de corporate governance en los Estados Miembros de la Unión Europea de 2009, conclusiones que hace suyas la Comisión Europea en el Plan de acción para la modernización del derecho de sociedades y mejora del gobierno corporativo en la Unión Europea, admitiendo importantes carencias en los informes de gobierno corporativo, que apenas facilitan información sobre la falta de seguimiento de las recomendaciones. Comisión de las Comunidades Europeas, COM/2012/0740 final, Comunicación de la Comisión al Parlamento Europeo, al Comité Económico y Social Europeo y al Comité de las Regiones, Plan de acción, Derecho de sociedades europeo y gobierno corporativo, Un marco jurídico moderno para una mayor participación de los accionistas y la viabilidad de las empresas, 7 (Comisión de las Comunidades Europeas, Estrasburgo, 12 de diciembre de 2012). Disponible en: http://eur-lex.europa.eu/legal-content/ES/TXT/?uri=CELEX\%3A52012DC0740 
(Deutscher Corporate Governance Kodex, DCGK) ${ }^{46}$, que en su preámbulo afirma que se dirige principalmente a las sociedades cotizadas y recomienda su adopción a las no cotizadas. En el mismo sentido se pronuncia el Código austriaco de gobierno corporativo (Österreichischer Corporate Governance Kodex) ${ }^{47}$. La postura de estos códigos da cuenta de una nueva política tendente a extender las normas de buen gobierno a la sociedad no cotizada a partir de un mismo cuerpo normativo, a diferencia de la experiencia en otros países europeos en que se han elaborado códigos específicos de buen gobierno con recomendaciones dirigidas exclusivamente a este tipo societario. Entre ellos cabe citar el Código belga ${ }^{48}$, la Guía Británica $^{49}$, España ${ }^{5051}$ y otras iniciativas similares en Francia, España, Finlandia, Países Bálticos o fuera de la Unión Europea (Albania y

46 Alemania, Código alemán de gobierno corporativo (Deutscher Corporate Governance Kodex, DCGK, German Corporate Governance Code, as amended on May 5, 2015 with decisions from the plenary meeting of May 5, 2015). Disponible en: http://www.dcgk.de/de/kodex.html, http://www.dcgk.de/en/code.html

47 Austria, Código austriaco de gobierno corporativo (Österreichischer Corporate Governance Kodex, 2012, Austrian Code of Corporate Governance as amended in January 2015). Disponible en: http://www.corporate-governance.at/kodex.htm, http://www.corporate-governance. at/pdf/CG_Kodex_EN_Jaenner_2015_v3.pdf

48 Bélgica, Código belga de gobierno corporativo (Belgian Code on Corporate Governance, 9 December 2004). Disponible en: http://www.corporategovernancecommittee.be/en/about2009-code/2009-belgian-code-corporate-governance

49 Reino Unido, The UK Corporate Governance Code (The Financial Reporting Council Limited, London, April 2016). Disponible en: https://www.frc.org.uk/Our-Work/Publications/ Corporate-Governance/UK-Corporate-Governance-Code-April-2016.pdf

$50 \mathrm{Si}$ bien en España se discutió esta materia, en el resultado final del proceso de reforma basado en las propuestas de la Comisión de Expertos - Ley 31/2014 de reforma de la Ley de Sociedades de Capital (LSC) para la mejora del gobierno corporativo y el nuevo Código de Buen Gobierno de las Sociedades Cotizadas (CBGSC) de febrero de 2015 - no se contempla referencia específica alguna a un posible código para sociedades no cotizadas. La reforma de la LSC concreta cambios relevantes para todo tipo de sociedades, en los Títulos V y VI básicamente, y cambios notables para las sociedades cotizadas en su Título XIV. El CBGSC, por su parte, dirige sus recomendaciones exclusivamente a las sociedades cotizadas, basándose en el principio de "cumplir o explicar". España, Ley 31/2014, de 3 de diciembre, por la que se modifica la Ley de Sociedades de Capital para la mejora del gobierno corporativo, 293 Boletín Oficial del Estado, BOE, 4 de diciembre de 2014. Disponible en: https://www.boe. es/diario_boe/txt.php?id=BOE-A-2014-12589. España, Código de Buen Gobierno de las Sociedades Cotizadas, CBGSC (Comisión Nacional del Mercado de Valores, CNMV, Madrid, febrero de 2015). Disponible en: http://www.cnmv.es/docportal/publicaciones/codigogov/codigo_buen_gobierno.pdf. TOMÁs Garicano-RoJas \& Pablo HafNer, Recomendaciones de buen gobierno corporativo para empresas no cotizadas, 8 (Centro de Buen Gobierno, Madrid, 2016). Disponible en: http://www.centrobuengobierno.ie.edu/wp-content/uploads/sites/87/2013/11/ Recomendaciones-Buen-Gobierno-Empresas-No-cotizadas-actualizado.pdf

51 Instituto de Consejeros Administradores, ICA, Principios de buen gobierno corporativo para empresas no cotizadas: código de buenas prácticas para el consejo, los consejeros y administradores (Instituto de Consejeros Administradores, ICA, Madrid, diciembre de 2005). Disponible en: http://www.ecgi.org/codes/documents/ica_cgp_non_listed_2006_es.pdf 
Suiza). La extensión de este fenómeno entre los Estados miembros de la Unión Europea también ha propiciado la aparición de iniciativas paneuropeas. La más relevante ha sido la que ha llevado a cabo la Confederación Europea de Asociaciones de Directivos (ecoDa) ${ }^{52}$ con la preparación de unos principios de gobierno corporativo para sociedades no cotizadas, que se presentó en el Parlamento Europeo el 24 de marzo de $2010^{53}$.

No se trata de un fenómeno exclusivamente europeo, sino global. En el ámbito internacional, la OCDE ha visto las posibilidades que podría tener el gobierno corporativo para sociedades no cotizadas en aquellos Estados que, no teniendo un mercado de valores desarrollado, entran en la categoría de países emergentes y en aquellos otros que están realizando el proceso de transición hacia una economía de mercado. Por su parte, la Corporación Financiera Internacional (IFC), que es uno de los organismos que integran el Banco Mundial, ha preparado un manual específico para el gobierno de la empresa familiar ${ }^{54}$.

\section{REVISIÓN DE LA SITUACIÓN DEL DERECHO SOCIETARIO CHILENO}

\section{A. Incorporación del buen gobierno a la legislación chilena}

En 1854, se aprobó la primera Ley de Sociedades Anónimas (LSA), que se la definía como una "persona legal formada por un fondo común dividido en acciones con accionistas con responsabilidad limitada" y para su constitución se requería una autorización especial del Ministerio de Hacienda. En esta ley no había norma alguna sobre protección a los inversionistas, de modo que las reglas que regían los gobiernos corporativos quedaban entregadas a la definición o acuerdo de los accionistas, que se plasmaba en los

52 http://ecoda.org/about-ecoda/

53 European Confederation of Director's Associations, ecoDa, Corporate Governance Guidance and Principles for Unlisted Companies in Europe (ecoDa, Brussels, 2010). Disponible en: http:// ecoda.org/uploads/media/GUIDANCE_-_2010_CG_for_Unlisted_-_EU.pdf

54 SAnaA Abousaid, Manual IFC de Gobierno de Empresas Familiares (Corporación Financiera Internacional, IFC, Banco Mundial, Washington, 2008). Disponible en: http://www-wds. worldbank.org/external/default/WDSContentServer/WDSP/IB/2008/08/21/000333038_2008 0821025522/Rendered/PDF/450770WP0Box331siness1200801PUBLIC1.pdf 
estatutos de la sociedad sin mayor control. Esta situación comenzó a cambiar durante la primera mitad del siglo XX con base en un incremento del control estatal sobre estas sociedades. Así, en 1928 se creó la Inspección General de Sociedades Anónimas y Operaciones Bursátiles, que se fusionó en 1931 con el regulador de seguros y dio origen a la Superintendencia de Compañías de Seguros, Sociedades Anónimas y Bolsas de Comercio.

A partir de la década de 1960, se presentaron varias propuestas legales de relevancia. La concreción más relevante de estas iniciativas tuvo ocasión en 1981 con la entrada en vigencia de la Ley $18046^{55}$, sobre sociedades anónimas y Ley $18045^{56}$, sobre mercado de valores. La primera, además de eliminar el requisito para la constitución consistente en la autorización previa del gobierno, distingue dos clases de sociedades anónimas: abiertas y cerradas, y regula con mayor intensidad las primeras. También introdujo normas sobre la información que las sociedades entregan al mercado, protección a los accionistas minoritarios, aumento de los quórums para decisiones estratégicas, incorporación del derecho a retiro y reducción de los requisitos para llamar a juntas de accionistas extraordinarias. Con posterioridad a ello, en 2000, por medio de la Ley $19705^{57}$, se establecieron nuevas reglas sobre las ofertas públicas de adquisición de acciones (OPAS) a partir del caso Enersis ${ }^{58}$, y se modificaron los

55 Chile, Ley 18046, Ley sobre sociedades anónimas, LSA, Diario Oficial, 22 de octubre de 1981. Disponible en: http://www.leychile.cl/Navegar?idNorma=29473

56 Chile, Ley 18045, Ley de mercado de valores, LMV, Diario Oficial, 22 de octubre de 1981. Disponible en: http://www.leychile.cl/Navegar?idNorma=29472

57 Chile, Ley 19705 regula la oferta pública de adquisición de acciones (OPAS) y establece régimen de gobiernos corporativos, 36.842 Diario Oficial, 20 de diciembre de 2000. Disponible en: http://www.leychile.cl/Navegar?idLey $=19705$

58 En 1997, Enersis, el holding eléctrico más grande de Chile, se vendió en circunstancias irregulares, a Endesa España, empresa del mismo giro. Enersis era en principio una empresa pública (Chilectra metropolitana), que fue privatizada a finales de la década de $1980 \mathrm{con}$ el "mecanismo popular", según el cual los trabajadores y administradores podían adquirir acciones de la misma sociedad. El gerente general José Roberto Yuraszeck-Troncoso se transformó mediante este mecanismo, en un accionista mayoritario. Posteriormente, se realizaron transformaciones y reestructuraciones que transformaron a la empresa en un holding. El conglomerado de Chilectra fue creciendo y se transformó en el principal controlador de Enersis Chile que, a su vez, se transformó en una de las empresas más relevantes de América Latina. Cuando Endesa España hizo la oferta de compra de acciones, varias administradoras de fondos de pensiones, AFP, tenían participación en acciones; sin embargo, el poder de las AFP en la empresa era mínimo. Cada chispa - empresa de menor tamaño que poseía acciones de Enersis - tenía acciones de dos tipos: A y B; las primeras tenían derecho a un mayor dividendo pero no tenían derecho de voto, de manera que Enersis era controlada por las acciones de clase $\mathrm{B}$, aun cuando su representación era mínima en la compañía (menos del $1 \%$ ). Endesa España negoció directamente con los controladores y ofreció pagar más de 800 
mecanismos de gobiernos corporativos vinculados con el funcionamiento y las responsabilidades del directorio ${ }^{59}$.

Las reformas introducidas en las últimas décadas provocaron un impacto relevante en la economía chilena, al ubicar a este país como uno de los mercados bursátiles más grandes de América Latina. Esto se explica porque estas modificaciones permitieron un aumento del grado de información en los mercados y un mayor reconocimiento de los derechos de los accionistas minoritarios, lo cual incentivó el desarrollo de inversores institucionales, acompañado de un mayor nivel de actividad financiera. No obstante ello, ciertos elementos se fueron vislumbrando como barreras para un mayor desarrollo del mercado, entre ellos destaca el alto nivel de concentración de la propiedad en el sector corporativo, el predominio de grupos empresariales de estructura piramidal y un bajo nivel de rotación de accionistas ${ }^{60}$. A partir de la reforma introducida por la Ley $20382^{61}$, sobre gobiernos corporativos, se pretendía subsanar estas barreras. En efecto, esta ley introdujo variadas modificaciones al régimen de las sociedades ${ }^{62}$ con la finalidad de alcanzar altos

veces más las acciones tipo B que las A (se ofreció $\$ 220$ por las acciones tipo A y $\$ 185.000$ por la de tipo B). Adicionalmente, Endesa les ofreció a las acciones B comprar a un precio preferencial sus propias acciones y mantener un rol de administración por al menos 5 años. Las AFP protestaron por esta situación y lograron revocar la operación en los tribunales de justicia, en el polémico caso Chispas. Endesa logró la compra de Enersis finalmente en 1999, pero los antiguos controladores fueron finalmente excluidos. Chile, Corte Suprema, Tercera Sala, Causa 4261/2004, Resolución 13925, 7 de julio de 2005, MacKenna Echaurren, Luis Fernando y otros con Superintendencia de Valores y Seguros, Recursos de casación en el fondo y en la forma. Extracto disponible en: http://corte-suprema-justicia.vlex.cl/vid/-255182466

59 Para un análisis sobre la evolución de la normativa legal en Chile, Fernando Lefort \& EduARdo Walker, The Effects of Economics and Political Shocks on Corporate Governance Systems in Chile, 2 Revista Abante, 2, 183-206 (2000). Disponible en: https://ideas.repec.org/a/pch/abante/ v2y2000i2p183-206.html, http://eacc10.puc.cl/files/ABT/Contenidos/Vol-2-N2/5\%20Walker\%20 Lefort.pdf

60 Sobre esta materia y los diferentes estudios que se han realizado sobre este punto, Gonzalo IsLAs-RoJas, Gobierno corporativo: teoría económica, principios de la OCDE y la Ley $N^{\circ} 20.382$, en Gobiernos corporativos. Aspectos esenciales de las reformas a su regulación, 9-44, 23-30 (Javier Wilenmann, coord., Universidad Adolfo Ibáñez, Abeledo Perrot, Thomson Reuters, Santiago, 2011).

61 Vigente desde el 1 de enero de 2010. Chile, Ley 20382 introduce perfeccionamientos a la normativa que regula los gobiernos corporativos de las empresas, 39.498 Diario Oficial, 29 de octubre de 2009. Disponible en: http://www.leychile.cl/Navegar?idNorma=1007297

62 La reforma no introduce cambios estructurales en la legislación societaria, que conserva su tradicional arquitectura, no así respecto de los deberes y responsabilidades de los administradores, materia en la que la ley en cuestión sí introduce modificaciones a la LSA y a la Ley de Mercado de Valores. Chile, Ley 20382 introduce perfeccionamientos a la normativa que regula los gobiernos corporativos de las empresas, 39.498 Diario Oficial, 29 de octubre de 2009. Disponible en: http://www.leychile.cl/Navegar?idNorma=1007297. Chile, Ley 18046, Ley sobre sociedades anónimas, LSA, Diario Oficial, 22 de octubre de 1981. Disponible 
estándares internacionales en materia de gobierno corporativo, lo que le permitiría a Chile cumplir los compromisos contraídos en su proceso de integración a la $\mathrm{OCDE}^{63}$. En este contexto, se logra perfeccionar el régimen jurídico ${ }^{64}$ al modificar la Ley de Sociedades Anónimas (LSA, Ley 18046), la Ley de Mercado de Valores (LMV, Ley 18045) y el Código de Comercio ${ }^{65}$, en diferentes aspectos.

En líneas generales, tales modificaciones se centran en aumentar el flujo de información que deben entregar las sociedades, tanto a sus propios accionistas como a las entidades fiscalizadoras; asegurar una adecuada supervisión de los mercados; permitir mayor fluidez de las operaciones; y proteger a los accionistas minoritarios. Cuatro principios subyacen a esta ley: 1. De la transparencia. Con ella se pretendió incrementar el flujo de información al mercado, para permitir a los accionistas y al regulador — Superintendencia de Valores y Seguros, SVS - un mayor control y eficacia en la supervisión y evaluación de las sociedades. Por otra parte, y con el fin de evitar abusos de la información privilegiada ${ }^{66}$, se previó que el órgano de administración tuviese un papel determinante en la definición de políticas que promuevan la transparencia. 2. De

en: http://www.leychile.cl/Navegar?idNorma=29473. Chile, Ley 18045, Ley de mercado de valores, LMV, Diario Oficial, 22 de octubre de 1981. Disponible en: http://www.leychile.cl/ Navegar?idNorma $=29472$

63 Sobre estas reformas, Osvaldo Lagos-Villarreal, Reformas al gobierno de las sociedades contenidas en la ley $N^{\circ}$ 20.382. Un gesto al equilibrio, en Gobiernos corporativos. Aspectos esenciales de las reformas a su regulación, 45-79 (JAVIER WiLENMANN, coord., Universidad Adolfo Ibáñez, Abeledo Perrot, Thomson Reuters, Santiago, 2011).

64 María Fernanda Vásquez-Palma, Una aproximación a los modelos existentes en materia de Gobiernos Corporativos y la elección de Chile a partir de las reformas incorporadas por la Ley 20.832, en Jornadas Chileno-Uruguayas de Derecho Comercial, 143-155 (Librotecnia, Santiago, 2011).

65 Chile, Código de Comercio, Diario Oficial, 23 de noviembre de 1865. Disponible en: https:// www.leychile.cl/Navegar?idNorma $=1974$

66 ANTONio BASCUÑán-Rodríguez, La regulación de la información privilegiada en el mercado de valores después de la ley $N^{\circ} 20.382$, en Gobiernos corporativos. Aspectos esenciales de las reformas a su regulación, 87-137 (JAVIER WILENMANN, coord., Universidad Adolfo Ibáñez, Abeledo Perrot, Thomson Reuters, Santiago, 2011). EnRiQue AlCAlde-Rodríguez, Uso de información privilegiada: algunas consideraciones sobre el sentido y alcance de la prohibición en relación con su sujeto, objeto y sanción, 27 Revista Chilena de Derecho, 1, 11-28 (2000). Disponible en: https://dialnet.unirioja.es/servlet/articulo?codigo=2650196. Arturo Prado-PugA, Acerca del concepto de información privilegiada en el mercado de valores chileno: su alcance, contenido y limites, 30 Revista Chilena de Derecho, 2, 237-269 (2003). Disponible en: https://dialnet.unirioja.es/descarga/articulo/2650285.pdf. María Fernanda VÁsQuez-Palma, Revisión del ámbito de aplicación subjetivo y objetivo de la noción de uso de información privilegiada en Chile: un examen de la normativa a la luz de las tendencias doctrinales y jurisprudenciales, 17 Revista de Derecho, Universidad Católica del Norte, Coquimbo, 2, 239-297 (2010). Disponible en: http:// www.redalyc.org/articulo.oa?id=371041341010 
la corrección de asimetrías de información y reducción de costes de información y coordinación. Conforme este principio, en general, los accionistas minoritarios no tienen incentivo en la inversión debido a las dificultades que enfrentan para ejercer sus derechos, lo que provoca problemas de agencia, y riesgos de abuso por parte de quienes gozan de ventajas de información y coordinación, con la consiguiente menor profundidad y desarrollo de los mercados. Asumiendo esta deficiencia del sistema, la ley consagró mecanismos para que los accionistas y el público general tuviesen acceso a la información completa y oportuna, lo cual disminuye los problemas de asimetría de información, de agencia y el riesgo de abuso. 3. Del fortalecimiento de los derechos de los accionistas minoritarios. En concordancia con lo expresado, y como una forma de resolver los inconvenientes que afectaban a los accionistas minoritarios y al mercado, la ley introdujo la figura del director independiente como un mecanismo idóneo para la defensa de ambos actores. Este director, que actúa por medio de un comité de directores, se configuró como una herramienta eficaz en la protección de los intereses de los accionistas minoritarios y en la mejora del flujo de la información al mercado, lo que evita que los accionistas que ostentan el control de la sociedad priven a los restantes accionistas de sus legítimos derechos. 4. De la autodeterminación. Los accionistas, por medio de la junta o del consejo, debían tomar las decisiones clave acerca de cómo proceder en casos individuales; esta posibilidad se previó para atender las circunstancias particulares de cada sociedad y sus preferencias.

Resumidamente entonces, esta ley buscó aumentar el flujo de información al mercado, permitiendo a los accionistas y al regulador una mejor supervisión y evaluación de la empresa, y la prohibición del uso de información privilegiada tanto en la compra como en la venta de acciones; por otra parte, se persiguió un mejor funcionamiento del directorio, para enfatizar la figura del director independiente y el comité de directores. En cuanto a las operaciones con partes relacionadas y conflictos de interés, la ley incorporó un conjunto de regulaciones y restricciones a los directores comprometidos en estas transacciones, para someterlos a un régimen estricto de responsabilidad. Finalmente, en lo que concierne a las juntas de accionistas se establecieron medidas para incrementar 
la participación de los accionistas minoritarios, lo que favorece la toma de decisiones ${ }^{67}$.

\section{B. ¿Es posible extrapolar los principios de buen gobierno corporativo a las sociedades no cotizadas en la legislación chilena?}

En Chile, al igual que en el derecho comparado, la noción de sociedades no cotizadas también se construye por exclusión. El artículo 2 de la Ley de sociedades anónimas 18046 (1981) dispone que: "Las sociedades anónimas pueden ser de tres clases: abiertas, especiales o cerradas. Son sociedades anónimas abiertas aquellas que inscriban voluntariamente o por obligación legal sus acciones en el Registro de Valores. Son sociedades anónimas especiales las indicadas en el Título XIII de esta ley. Son sociedades anónimas cerradas las que no califican como abiertas o especiales (...)". Las primeras están afectas a la supervisión de la Superintendencia de Valores y Seguros, a diferencia de las cerradas, control que se da fundamentalmente por su forma de financiamiento (mercado de valores) e intereses protegidos ${ }^{68}$. De la mano de ello, la Ley de mer-

67 Sobre algunos informes realizados en relación con los cambios establecidos por la Ley 20382, en materia de gobiernos corporativos: http://centrogobiernocorporativo.uc.cl/proyectos-deinvestigacion.html

68 La sociedad anónima siempre tuvo esta supervisión e, incluso, se solicitaba una autorización estatal de existencia. En efecto, ya en 1865, el Código de Comercio disponía una forma de supervisión de las sociedades anónimas. El artículo 436, de su edición original, establecía que "El Presidente de la República podrá nombrar un comisario que vigile las operaciones de los administradores y dé cuenta de la inejecución o infracción de los estatutos". Por su parte, la Ley 1712 de 1904 reglamentó el funcionamiento de las compañías de seguros, las que estaban sujetas a la designación de "inspectores de oficinas fiscales para que vigilen las operaciones, libros y cuentas de las compañías nacionales y agencias de compañías extranjeras". Chile, Ley 1712 de 1904, reglamenta el funcionamiento de las compañías de seguros, Diario Oficial, 19 de noviembre de 1904. Disponible en: http://www.leychile.cl/Navegar?idNorma=22868. Las operaciones de bolsa fueron reglamentadas por el Decreto Ley 93 de 1924. En él se establece la existencia de un inspector en Santiago y otro en Valparaíso. El mismo año se complementó el régimen legal de las sociedades anónimas, por medio del Decreto Ley 158 , en especial respecto de la responsabilidad de los organizadores que invitaban al público a suscribir acciones y a la de los peritos técnicos que las informaban; y por último, creó la Inspección de Sociedades Anónimas para que "se ejercite permanentemente la vigilancia pública de que habla el artículo 436 de Código de Comercio". Luego en 1927, la Ley 4228 derogó la Ley 1712 y creó la Superintendencia de Compañías de Seguros. Chile, Ley 4228 de 1927, Diario Oficial, 21 de diciembre de 1927. Disponible en: http://www.leychile.cl/Navegar?idNorma=24585. En 1928, la Ley 4404 funda la Inspección General de Sociedades Anónimas y Operaciones Bursátiles. Chile, Ley 4404 de 1928, crea la Inspección General de Sociedades Anónimas y Operaciones Bursátiles, Diario Oficial, 10 de septiembre de 1928. Disponible en: http://www.leychile.cl/ Navegar?idNorma=24712. El DFL 251 de 22 de mayo de 1931 fusionó ambos organismos, 
cado de valores (LMV, Ley 18045), en sus artículos $5^{69}$ y $6^{70}$, dispone que las sociedades que cotizan en el mercado de valores chileno son principalmente las anónimas abiertas y aquellas anónimas que voluntariamente así lo soliciten o que por obligación legal deban registrarse en el Registro de Valores. De este modo, son sociedades no cotizadas las sociedades anónimas cerradas, por acciones, de responsabilidad limitada, colectiva y en comandita, todas ellas con características y cuerpos normativos diferenciados.

Un rasgo que debemos destacar en el diseño normativo chileno tiene relación con el hecho que la ley no hace mayores distinciones entre las sociedades anónimas, pues su normativa es unitaria, de manera que las regula de forma análoga, sin importar si cotizan o no en los mercados de valores, de manera que su régimen legal es aplicable, en general, a todas las sociedades de este tipo (abiertas, cerradas y especiales) $^{71}$. Esta precisión no es de menor envergadura, si consideramos que el grueso del régimen legal de las sociedades anónimas está integrado por disposiciones de carácter imperativo, indisponibles para los socios, lo que se justifica plenamente para las sociedades anónimas abiertas, no así para las cerradas respecto de las cuales naturalmente la autonomía privada debería tener una mayor cabida. Una forma de entender esta aplicación normativa podría deberse a la potencialidad de las sociedades cerradas para

bajo el nombre de Superintendencia de Sociedades Anónimas, Compañías de Seguros y Bolsas de Comercio. Chile, DFL 251 de 1931, compañías de seguros, sociedades anónimas y bolsas de comercio, Diario Oficial, 22 de mayo de 1931. Disponible en: https://www.leychile. cl/Navegar?idNorma=5201. Finalmente, el DL 3538, de 23 de diciembre de 1980, establece la creación definitiva de la Superintendencia de Valores y Seguros, continuadora legal de la fundada en 1931. Chile, DL 3538 de 1980, crea la Superintendencia de Valores y Seguros, Diario Oficial, 23 de diciembre de 1980. Disponible en: http://www.leychile.cl/Navegar?idNorma=7168

69 Que dispone: "La Superintendencia llevará un Registro de Valores el cual estará a disposición del público. En el Registro de Valores se deberán inscribir: a) Los emisores de valores de oferta pública; b) Los valores que sean objeto de oferta pública; c) Las acciones de las sociedades anónimas que tengan 500 o más accionistas o, a lo menos, el 10\% de su capital suscrito pertenezca a un mínimo de 100 accionistas, excluidos los que individualmente o a través de otras personas naturales o jurídicas, excedan dicho porcentaje, y d) Las acciones emitidas por sociedades anónimas que voluntariamente así lo soliciten o que por obligación legal deban registrarlas(...)".

70 Que dispone: "Solo podrá hacerse oferta pública de valores cuando estos y su emisor hayan sido inscritos en el Registro de Valores. De este modo, son aplicables a estos tipos societarios ambos sistemas normativos: el que rige a las sociedades anónimas y el del mercado de valores".

71 Sobre las prácticas de gobiernos corporativos en Chile: RoDRIGo GARCíA, Norma de información sobre prácticas de gobierno corporativo en Chile (Superintendencia de Valores y Seguros, Working paper, Santiago de Chile, 2014). Disponible en: https://www.svs.cl/portal/publicaciones/ 610/articles-16379_doc_pdf.pdf 
acceder al mercado de valores, luego de cumplir ciertos requisitos; otro fundamento habría que encontrarlo en la complejidad de estas sociedades y la necesidad de tornar más eficaz y protector su actuar, considerando que estas sociedades participan del mercado financiero con capitales relevantes.

Con todo, en lo que respecta a los principios de gobiernos corporativos, si bien cautelan algunas materias de forma simétrica, no tratan ambas sociedades (abiertas y cerradas) bajo el mismo manto protector. En efecto, la Ley 20382 introdujo varias modificaciones que afectan a las sociedades anónimas abiertas y cerradas; y otras, en cambio, que solo refieren a las primeras. Entre aquellas que no distinguen según el tipo societario destacan: a. Responsabilidad respecto a los libros y registros sociales (artículo 7 LSA, Ley 18046), en la medida que no es el gerente de la sociedad, sino su directorio, el responsable de la custodia y regularidad de los libros sociales, si bien esta función puede delegarse (en el mismo gerente, el abogado de la compañía, etc.). El directorio debe definir quién será responsable por los libros y registros, debiendo tomar este acuerdo en una sesión legalmente constituida. b. Quórum de constitución del directorio puede formarse con mayoría de directores suplentes (artículo 47 LSA, Ley 18046), sin que hoy se discuta si el directorio debe sesionar con la asistencia de la mayoría absoluta de los directores titulares, toda vez que expresamente se permite sesionar válidamente con una mayoría de directores suplentes. c. Posibilidad de llevar a efecto acuerdos del directorio previo a la aprobación del acta respectiva (artículo 48 LSA, Ley 18046), la unanimidad de los directores que concurrieron a una sesión puede disponer que los acuerdos adoptados se lleven a efecto sin esperar la aprobación del acta, dejando constancia de esta situación en un documento firmado por todos ellos (que vendría a ser un "extracto" del acta, relativo a un acuerdo puntual que requiera ser ejecutado de manera inmediata). d. Posibilidad de firmar las actas de directorio mediante firma electrónica (artículo 48 LSA, Ley 18046), si bien no es del todo clara su aplicación a las sociedades anónimas cerradas, SAC, la SVS podrá autorizar la adopción de mecanismos que permitan el uso de firma electrónica u otros medios tecnológicos, lo que viene a complementar la realización de las sesiones "virtuales o a distancia", al permitirse ahora que no solo la asistencia del direc- 
tor, sino también su firma en el acta, puedan tener lugar en forma remota. e. Autoconvocatoria a juntas de accionistas (artículo 60 LSA, Ley 18046). Se consagra en forma expresa la posibilidad de autoconvocatoria de juntas de accionistas a las que concurran la totalidad de las acciones emitidas con derecho a voto. f. Sistemas de votación en juntas de accionistas (artículo 62 LSA, Ley 18046). Por otra parte, se establece que toda votación deberá realizarse mediante un sistema que asegure la simultaneidad de la emisión de votos o, bien, en forma secreta, debiendo el escrutinio llevarse a cabo en un solo acto público, y de manera tal que en ambos casos pueda conocerse, con posterioridad y en forma pública, cómo sufragó cada accionista ${ }^{72}$. g. Ampliación de las materias que requieren Quórum especial de 2/3 de las acciones con derecho a voto (artículo 67 LSA, Ley 18046), se incluyen como materia de Quórum especial: (i) la enajenación del $50 \%$ o más del activo de una filial, siempre que esta represente al menos un $20 \%$ del activo de la sociedad; (ii) la enajenación de acciones en esa filial en términos tales que implique perder su control, y (iii) la aprobación o ratificación de contratos con partes relacionadas. $h$. Rol de la sociedad respecto de pactos de accionistas relativos a cesión de acciones (artículo 14 LSA, Ley 18046), y se aclaró que la existencia de pactos entre accionistas que limiten o que de cualquier otra forma se refieran a la cesión de sus acciones (por ejemplo, estableciendo derecho de adquisición preferente) no afectarán de manera alguna la obligación de la sociedad de inscribir sin más trámite los traspasos de acciones que se le presenten, sin corresponderle calificar si las restricciones a la cesión de acciones acordadas en un pacto han sido cumplidas o no.

Entre aquellas modificaciones que solo afectan las sociedades anónimas abiertas, podemos encontrar las que enunciamos a continuación ${ }^{73}$ :

72 Al respecto, la SVS dictó la NCG 273, que regula esta materia para las sociedades anónimas abiertas. Chile, Superintendencia de Valores y Seguros, SVS, Norma de Carácter General 273, NCG 273, Regula sistemas de votacion en juntas de accionistas, 13 de enero de 2010. Disponible en: http://www.svs.cl/normativa/ncg_273_2010.pdf

73 En esta línea, debemos considerar que la SVS ha emitido diversas normas con el propósito de fortalecer los gobiernos corporativos de las sociedades anónimas abiertas. Las más relevantes son: las normas de carácter general (NCG) 341 sobre gobiernos corporativos, derogada por la norma 385; y la NCG 386, que modifica la norma 30. Entre los principales cambios que propicia la NCG 385 destacan: fomentar la adopción de políticas en materia de responsabilidad social y desarrollo sostenible, referido en particular a la composición del directorio y en la designación de ejecutivos principales de la sociedad; fomentar la difusión de información 
1. Acciones con preferencias. De conformidad a lo expresado en el artículo 20 de la LSA, Ley 18046, las acciones pueden ser ordinarias o preferidas. Las preferencias deberán constar en los estatutos sociales y en los títulos de las acciones deberá hacerse referencia a ellas. No podrán estipularse preferencias sin estipular el plazo de vigencia o que consistan en el otorgamiento de dividendos que no provengan de utilidades de ejercicio o de utilidades retenidas y sus respectivas revalorizaciones. Se establece que las sociedades anónimas abiertas podrán contener preferencias que otorguen a una serie de acciones preeminencia en el control de la sociedad por un plazo máximo de 5 años, pudiendo prorrogarse por acuerdo de la junta extraordinaria de accionistas. En las sociedades anónimas cerradas no se establece ninguna limitación a este respecto, de manera que será posible que estas sociedades establezcan acciones preferentes para controlar la sociedad con la única limitación de señalar un plazo, sin importar el tiempo que se otorga a estos efectos.

2. Operaciones con partes relacionadas. El artículo 44 de la LSA, Ley 18046, establece que la sociedad anónima cerrada solo podrá celebrar actos y contratos que involucren montos relevantes en los

a los accionistas y público general respecto de las políticas, prácticas y efectividad de las mismas, en materia de responsabilidad social y desarrollo sostenible; mejorar la calidad y confiablidad de la información contenida en la autoevaluación de los directorios mediante la evaluación de un tercero ajeno a la sociedad; promover la adopción de principios, directrices y recomendaciones nacionales e internacionales; explicitar el tratamiento de los conflictos de interés y los procedimientos de actualización del Código de Conducta del directorio. En tanto, las modificaciones introducidas en la norma 386 contempla los siguientes aspectos: diversidad en el directorio (género, nacionalidad, edad y antigüedad); diversidad en la gerencia general; en la organización; y brecha salarial por género. Chile, Superintendencia de Valores y Seguros, SVS, Norma de Carácter General 341, NCG 341, Establece normas para la difusión de información respecto de los estándares de gobierno corporativo adoptados por las sociedades anónimas abiertas, 29 de noviembre de 2012. Disponible en: http://www.svs.cl/normativa/ ncg_341_2012.pdf. Chile, Superintendencia de Valores y Seguros, SVS, Norma de Carácter General 385, NCG 385, Establece normas para la difusión de información respecto de las prácticas de gobierno corporativo adoptados por las sociedades anónimas abiertas. Deroga norma de carácter general 341 de 2012, 8 de junio de 2015. Disponible en: http://www.svs.cl/ normativa/ncg_385_2015.pdf. Chile, Superintendencia de Valores y Seguros, SVS, Norma de Carácter General 386, NCG 386, Modifica norma de carácter general 30 de 1989 en los términos que indica, 8 de junio de 2015. Disponible en: http://www.svs.cl/normativa/ncg_386_2015.pdf. Chile, Superintendencia de Valores y Seguros, SVS, Norma de Carácter General 30, NCG 30, Establece normas de inscripción de emisores y valores de oferta pública en el registro de valores, su difusión, colocación y obligaciones de información consiguientes (SAA, EVOP Y EIRV), 10 de noviembre de 1989. Disponible en: http://www.svs.cl/normativa/ncg_30_1989. pdf. Chile, Superintendencia de Valores y Seguros, SVS, Informe final. Fortalecimiento de estándares de gobierno corporativo de las sociedades anónimas abiertas (Superintendencia de Valores y Seguros, SVS, Santiago, junio de 2015). Disponible en: http://www.svs.cl/portal/ principal/605/articles-20924_doc_pdf.pdf 
que uno o más directores tengan interés por sí o como representantes de otra persona, cuando estas operaciones sean conocidas y aprobadas previamente por el directorio y se ajusten a las condiciones de equidad similares a las que actualmente prevalecen en el mercado, salvo que los estatutos autoricen la realización de tales operaciones sin sujeción a las mencionadas condiciones. El directorio deberá pronunciarse con la abstención del director con interés. En el acta de la sesión del directorio deberá dejarse constancia de las deliberaciones para aprobar los términos y condiciones de los respectivos contratos, y tales acuerdos serán informados en la próxima junta de accionistas por su presidente, y debe mencionarse esta materia en su citación. A continuación, se señalan los casos en que se entiende que el director tiene interés en la negociación, acto, contrato u operación. Entre ellas se señalan aquellas operaciones en las que deban intervenir él mismo, su cónyuge o sus parientes hasta el segundo grado de consanguinidad o afinidad (a); las sociedades o empresas en las que sea director o dueño, directamente o por medio de otras personas naturales o jurídicas, de un 10\% o más de su capital (b); las sociedades o empresas en las cuales alguno de los antes mencionados sea director o dueño, directo o indirecto, del $10 \%$ o más de su capital (c); y el controlador de la sociedad o sus personas relacionadas, si el director no hubiera resultado electo sin los votos de aquel o aquellos. Lo más complejo de esta regulación concierne a que sus efectos no inciden en la validez de la operación o contrato, sino que se traducen simplemente en el reconocimiento de una acción de indemnización de los perjuicios que ocasione la infracción a la norma. Para las sociedades anónimas abiertas rige el Título XVI que trata esta materia en sus artículos 146 y siguientes de la LSA, Ley 18046. En esta normativa, la sanción tampoco es la nulidad, sino la posibilidad de impetrar una acción de reembolso (artículo 148 LSA, Ley 18046), de manera que la diferencia está en el procedimiento, causales y resguardos que se contemplan para cada caso.

Información y transparencia. De acuerdo al artículo 46 de la LSA, Ley 18046, el directorio deberá proporcionar a los accionistas y al público, las informaciones suficientes, fidedignas y oportunas que la ley y, en su caso, la Superintendencia determinen respecto de 
la situación legal, económica y financiera de la sociedad. Se dispone que en las sociedades anónimas abiertas, el directorio será responsable de adoptar las medidas necesarias para evitar que la información sea divulgada a personas diferentes de aquellas que por su cargo, posición o actividad en la sociedad deban conocer esta información, antes de ser puesta a disposición del público y los accionistas. Para las sociedades anónimas cerradas, no se establece este deber, lo que es cuestionable si se considera que en ellas también estaría justificado este resguardo respecto de la información. Por su parte, el artículo 7 de este cuerpo legal dispone que la sociedad deberá mantener en la sede principal y en la de sus agencias o sucursales, ejemplares actualizados de sus estatutos firmados por el gerente y una lista actualizada de los accionistas. Agrega que las sociedades anónimas abiertas que dispongan de sitios de internet, pueden publicarlos por este medio. Al respecto, nuevamente se omite tal posibilidad para las sociedades anónimas cerradas, sin divisar fundamento para tal distinción. En esta misma línea, el artículo 76 expresa que las sociedades anónimas abiertas deberán publicar en su sitio de internet la información sobre sus estados financieros y el informe de auditores externos con no menos de 10 días de anticipación a la fecha que se celebre la junta que se pronunciará sobre este asunto.

Directores independientes. Esta figura está prevista para las sociedades anónimas abiertas (artículo 50 bis). Señala este precepto que las sociedades anónimas abiertas deberán designar al menos un director independiente y un comité de directores, cuando tengan un patrimonio al equivalente a 1.500 .000 unidades de fomento o al menos, cuando el 12,5\% de sus acciones emitidas con derecho a voto esté en poder de accionistas que individualmente controlen o posean menos del $10 \%$ de tales acciones. El comité tendrá las facultades y deberes que se establecen en la citada normativa, lo que liga el examen de informes de los auditores externos y clasificadores privados de riesgos, en su caso, que serán sugeridos a la junta de accionistas respectiva; examinar los antecedentes relativos a las operaciones con partes relacionadas; examinar sistemas de remuneraciones y planes de compensaciones de gerentes y ejecutivos principales y trabajadores de la sociedad; preparar un informe anual de su gestión en que se incluyen recomendaciones a los accionistas; 
y otras materias que señalen los estatutos sociales o le encomienden la junta de accionistas o el directorio. Nuevamente, resulta difícil entender, salvo que el criterio que justifique la figura del director independiente sea exclusiva para las sociedades anónimas abiertas, la razón por la cual no se prevé ni siquiera por la vía del ejercicio de la autonomía privada la incorporación de tal director a las sociedades cerradas.

Derechos de los accionistas. La adopción de acuerdos sobre ciertas materias otorga derecho a los accionistas disidentes para retirarse de la sociedad, previo pago por aquellas del valor de sus acciones. Entre las materias que otorgan este derecho están la transformación y fusión de la sociedad; las enajenaciones de más del 50\% de su activo, incluya o no su pasivo; el otorgamiento de cauciones; la creación de preferencias para una serie de acciones o aumento, prórroga o reducción de las ya existentes; el saneamiento de la nulidad causada por vicios formales de que adolezca la constitución de la sociedad o alguna modificación de sus estatutos diere ese derecho; y los demás casos que establezcan la ley o los estatutos. También dará derecho a retiro en favor de los accionistas minoritarios, que un controlador adquiera más de un $90 \%$ de las acciones de una sociedad anónima abierta. Nuevamente, surge la pregunta ¿por qué no extrapolar esta situación a las sociedades cerradas? Ello implicaría una mayor protección para los accionistas afectados por una decisión social que perjudica sus intereses o que no se aviene con ellos.

Más allá de la situación particular de la sociedad anónima cerrada, respecto de las restantes sociales no cotizadas, no existe un marco jurídico claro que recoja principios de buen gobierno a las restantes sociedades no cotizadas. Solo es posible encontrar ciertas normas particulares en la sociedad colectiva (artículos 386 y siguientes del Código de Comercio, CCo) que se refieren al derecho de oposición del socio respecto de algunos actos por parte de los otros socios, con independencia de si es minoritario o mayoritario (artículos 388 y 389 CCo); la adopción de acuerdos y sus implicancias respecto de terceros de buena fe (artículos $390 \mathrm{y}$ $391 \mathrm{CCo}$ ); ciertos resguardos de registro y transparencia (artículo $403 \mathrm{CCo}$ ); y la exigencia de un actuar ético por parte de los socios 
que se traduce en algunas prohibiciones (artículos 404 y 406 CCo). Estas disposiciones también son aplicables, por falta de disposición especial, a las sociedades de responsabilidad limitada. Por su parte, las sociedades en comanditas recogen algunas normas que aluden a la responsabilidad de los socios (artículos 476 y 477 CCo); los derechos de los socios (artículos 481 y 482 CCo.); las consecuencias frente a un actuar indebido de competencia desleal (artículo 488 $\mathrm{CCo}$ ); la adopción de acuerdos en las sociedades en comanditas por acciones (artículo $496 \mathrm{CCo}$ ) y los órganos que rigen en ella (artículos 498 y 499 CCo). La sociedad por acciones, finalmente, establece distintas normas que tienen por objeto facultar a las partes a efectuar los acomodos que les parezcan necesarios en pos de la adecuada marcha social (artículos 434, 435 y 437 CCo). Así mismo, establece los medios de comunicación que podrán ser utilizados entre la sociedad y los accionistas (445 CCo).

Como podemos observar, la situación de las sociedades que no cotizan en el mercado de valores chileno, presenta una regulación dispar, toda vez que no en todas se recogen normas que resguarden el buen gobierno. La justificación de esta idea podría encontrarse en el tamaño reducido de estas sociedades y el tipo de mercado por el que transitan; sin embargo, debemos considerar que muchas de estas poseen capitales nada despreciables y realizan actividades relevantes en el mercado, lo que provoca efectos en un número relevante de individuos; de la mano de ello, no solo podríamos enfocarnos en el mercado de valores, pues el mercado financiero en general también impacta en el desarrollo de la economía, de manera que su adecuado funcionamiento exige nuestra atención.

\section{Situación particular de ciertas sociedades anónimas especiales: compañias de seguros}

Mención aparte merecen las normas que se han dictado en materia de gobierno corporativo para sociedades anónimas especiales. Al respecto, cabe recordar que estas están normadas en el Título XIII de la Ley de Sociedades Anónimas, como compañías de seguros, reaseguros, las administradoras de fondos mutuos y bolsas de valores, para cuya existencia deben obtener una resolución de la Superintendencia de Valores y Seguros, SVS. Estas sociedades se 
rigen por las disposiciones legales y reglamentarias aplicables a las sociedades anónimas abiertas y a las disposiciones especiales que las rijan. No necesariamente serán emisoras de valores o cotizadas, de manera que solo deberán inscribirse en el Registro de Valores de la SVS aquellas que los emitan.

Con el propósito de cumplir de mejor forma su misión como organismo supervisor del mercado de seguros en Chile, en los últimos años, la SVS ha revisado sus sistemas de supervisión. En tal sentido, a partir del análisis de la experiencia y de recomendaciones internacionales en materia de regulación de seguros, en especial de la Asociación Internacional de Supervisores de Seguros, IAIS (International Association of Insurance Supervisors), la OCDE (Organización para la Cooperación y el Desarrollo Económicos), el Banco Mundial y el Fondo Monetario Internacional, la SVS decidió efectuar un proceso de modernización en su enfoque de supervisión, considerando para ello un modelo basado en riesgos. La NCG $309^{74}$ fue el primer paso concreto en la puesta en marcha del nuevo modelo de supervisión basada en riesgos para compañías de seguros. Los principios y buenas prácticas de gobierno corporativo aquí establecidos se consideraron fundamentales para una adecuada gestión de estas compañías de acuerdo a los intereses protegidos. Esta norma se complementó en diciembre de ese mismo año con la expedición de la NCG $325^{75}$, informando a la industria la metodología que la SVS aplicaría para llevar a cabo su evaluación de la solvencia en las aseguradoras, calidad de la gestión y gobierno corporativo.

La NCG 309 parte de la base de que la efectividad del gobierno corporativo de una compañía de seguros es un elemento esencial para su buen funcionamiento. La vigilancia efectiva de los negocios de una compañía de seguros por parte de su directorio resulta esencial para el mantenimiento de un modelo regulatorio eficiente

74 Chile, Superintendencia de Valores y Seguros, SVS, Norma de Carácter General 309, NCG 309, Principios de gobierno corporativo y sistemas de gestión de riesgo y control interno, 20 de junio de 2011. Disponible en: http://www.svs.cl/institucional/mercados/ver_archivo. php?archivo=/web/compendio/ncg/ncg_309_2011.pdf

75 Chile, Superintendencia de Valores y Seguros, SVS, Norma de Carácter General 325, NCG 325, Imparte instrucciones sobre sistema de gestión de riesgos de las aseguradoras y evaluación de solvencia de las compañías por parte de la Superintendencia. Deroga NCG 130 de 2002, 29 de diciembre de 2011. Disponible en: http://www.svs.cl/institucional/mercados/ver_archivo. php?archivo=/web/compendio/ncg/ncg_325_2011.pdf 
que permita a la autoridad supervisora considerar los procesos internos de la institución y focalizar de mejor forma el esfuerzo de supervisión necesario. Adicionalmente, en situaciones en que una compañía de seguros experimenta problemas, o en las cuales son necesarias acciones correctivas, el rol del directorio se torna más importante y requiere un significativo involucramiento en la búsqueda de soluciones y la adopción de las acciones correctivas pertinentes.

La Superintendencia evalúa la calidad de los gobiernos corporativos en la definición de sus políticas, planes y prioridades de supervisión respecto de cada aseguradora. Los principios y conceptos de gobierno corporativo señalados en la presente norma se ponderan en la evaluación de la Superintendencia, de acuerdo a la realidad de cada compañía, que reconoce la naturaleza, alcance, complejidad y perfil de sus negocios. De esta manera, y en consonancia con lo ya señalado, la aplicación de estos principios o conceptos pueden adoptar modalidades distintas en cada aseguradora.

El gobierno corporativo define roles, responsabilidades y rendición de cuentas, de manera que se aclara quién tiene el deber y el poder para actuar en nombre de un asegurador y bajo qué circunstancias. Plantea los requerimientos para documentar decisiones y otras acciones, y para informar a los grupos de interés las acciones del asegurador y su racionalidad. Así mismo, provee sanciones por el incumplimiento de la gestión o por una deficiente vigilancia o control; de este modo, el gobierno corporativo regula la asignación de poder y rendición de cuentas en las aseguradoras. Se señala que en la designación de los directores, se deberían considerar requisitos mínimos de idoneidad técnica y moral; estos requisitos apuntan por un lado a la necesidad de contar con directores que tengan las calificaciones profesionales y experiencia necesaria para ser capaces de entender temas técnicos complejos relacionados con el negocio de los seguros y evaluar el nivel de exposición al riesgo de la compañía y la calidad de sus sistemas de gestión de riesgos. También deben considerarse requisitos de integridad y comportamiento pasado en los negocios que garanticen un desempeño transparente, objetivo e independiente por parte de sus miembros. La NCG 309 plantea que deben considerarse políticas de capacitación especializada para los miembros del directorio, de modo que estos se mantengan 
informados y actualizados en relación con el desenvolvimiento de la actividad aseguradora.

Al mismo tiempo, considera mecanismos específicos para evaluar el desempeño del directorio. En este contexto, se destaca que el perfil profesional y la experiencia de los directores no necesariamente deben ser homogéneos; lo relevante es que el directorio posea una combinación adecuada de conocimientos y experiencia que favorezca su efectividad y buen desempeño colectivo. Estos mecanismos deben ser aplicados periódicamente y, por medio de ellos, identificar eventuales debilidades o vacíos en términos de conocimiento y experiencia que deben ser corregidos para una mejor gestión de la compañía.

El directorio puede delegar algunas de sus tareas a comités, conformados por directores y ejecutivos de la compañía o asesores externos, lo que permite que un pequeño grupo de miembros del directorio se focalice y especialice en áreas específicas, en pos de su eficiencia. Estos comités usualmente son los siguientes: Comité de auditoría; Comité de remuneración; Comité de ética y/o cumplimiento; Comité de administración de riesgo; Comité de inversiones o ALM; Comité técnico (incluyendo reaseguro); Comité de difusión; Comité de gobernabilidad; Comité de recursos humanos; Comité de desarrollo estratégico. Los comités que el directorio establezca para promover la efectividad de la gobernabilidad dependerán del tamaño, naturaleza, complejidad y el perfil de riesgo de la aseguradora; en este orden de ideas, el directorio debe definir claramente el mandato, autoridad y responsabilidades de cada uno de los comités establecidos, así como su conformación y los procedimientos generales de trabajo. Debe así mismo procurarse que los comités actúen con suficiente independencia, en especial, respecto de materias en las cuales puede haber conflictos de interés.

El directorio de una aseguradora debe considerar entre sus funciones y responsabilidades, al menos las siguientes materias: 1 . Establecer y vigilar la adecuada implementación de las estrategias y políticas generales de la aseguradora, incluyendo, por ejemplo: a. dirección estratégica y posicionamiento en el mercado; b. líneas de negocios y la introducción de nuevos productos; c. adquisiciones y alianzas estratégicas; d. estructura organizacional; e. negocios y transacciones intragrupales (empresas o personas relacionadas); f. 
administración de riesgo, incluyendo apetito y perfil de riesgo de la aseguradora; g. tarificación, suscripción, reservas técnicas y reaseguro; h. sistemas de control interno, incluyendo auditoría interna, cumplimiento y función actuarial; i. inversiones, administración de activos y pasivos y uso de productos derivados; $j$. remuneraciones y compensaciones; $k$. evaluación de las necesidades de capital y posición de solvencia; 1 . atención a clientes y manejo de siniestros y reclamos. Las estrategias y políticas deben establecerse por escrito y estar siempre sujetas a aprobación previa del directorio. Así mismo, deben ser revisadas al menos anualmente y adaptadas a la luz de cualquier cambio significativo en el ambiente interno o externo. Además, el directorio debe establecer y vigilar la adecuada implementación de un sistema de información interno, confiable, completo y oportuno, que ayude a la efectiva toma de decisiones del directorio y a un adecuado monitoreo a la alta gerencia. Es el deber del directorio requerir cualquier información no estipulada en los reportes internos de la aseguradora, que se estime necesaria para llevar a cabo sus funciones, incluyendo contar con asesoramiento externo independiente para mejorar la toma de decisiones y su monitoreo.

Así mismo, el directorio debe aprobar un código de ética y unos estándares de conducta que, entre otros tópicos, consideren: a. la obligación de cumplir la ley y las regulaciones; b. la obligación de cumplir las estrategias y políticas del asegurador; c. el esfuerzo por evitar los conflictos de interés, y de presentarse, diseñar un mecanismo para su resolución. Los miembros del directorio y la alta gerencia deberían evitar realizar otras labores en que sus intereses y deberes puedan entrar en conflicto con sus deberes para con la aseguradora; $d$. canales de comunicación para facilitar que los empleados informen posibles violaciones a la ley o las regulaciones, o potenciales fraudes tanto internos como externos, con las apropiadas medidas para proteger de represalias a los empleados que informan de anomalías; e. fomentar el trato justo para asegurados y empleados de la compañía; f. establecer mecanismos de comunicación e información con los distintos grupos de interés, incluyendo accionistas, asegurados, empleados, organismos supervisores y otros, dentro del marco legal y normativo vigente y políticas de remuneración y compensaciones para la alta gerencia 
de la compañía, consistentes con políticas de gestión de riesgos prudentes, que no incentiven la toma excesiva de riesgos, y vigilar su adecuada operación y cumplimiento. Así mismo, debe aprobar los lineamientos generales para la política de remuneración de los empleados de la compañía. La evaluación del directorio debe extenderse también a otras personas que realizan funciones relevantes en la gestión de la compañía, aun cuando no sean empleados de esta (ejemplo: asesores clave).

En cuanto a las funciones de gestión de riesgo y control, la aseguradora debe tener implementados: a. mecanismos sólidos y eficientes de identificación, evaluación, cuantificación, control, mitigación y monitoreo de los riesgos; b. sistemas y procedimientos adecuados que aseguren el cumplimiento de las estrategias y políticas internas, y de las leyes y regulaciones a las cuales está sujeta la compañía; c. controles internos apropiados que aseguren que se cumpla con la administración de riesgos y las políticas de cumplimiento; y d. una función de auditoría interna capaz de revisar y evaluar la suficiencia y efectividad de sus controles internos, así como también la entrega de informes sobre sus estrategias, políticas y procedimientos. Es responsabilidad del directorio de la compañía verificar que estas funciones se establezcan y operen en forma efectiva, y debe supervisar su desempeño.

Se agrega que la función del reaseguro es parte fundamental de la actividad de suscripción de riesgos de la aseguradora y, por lo tanto, toda compañía de seguros debe tener una política de reaseguro aprobada por su directorio y apropiada a su perfil de riesgos.

La política en cuanto al grupo controlador debe ser transparente y suficientemente divulgada, tanto en el ámbito interno (ejecutivos, empleados de la compañía) como en el externo (Superintendencia, auditores externos, clasificadores de riesgo, asegurados y público en general). El directorio y la alta gerencia de la compañía deben tener una adecuada comprensión de los negocios, operaciones y riesgos asociados al grupo controlador de la compañía, y en especial deben estar atentos a cualquier riesgo de contagio desde el grupo hacia esta. Los sistemas de monitoreo y control de riesgos deben mantenerse en la compañía, para poder identificar y mitigar oportunamente el contagio derivado del grupo controlador. 
La aseguradora debe difundir toda la información necesaria, $\mathrm{y}$ cualquier otra información que pueda beneficiar a sus grupos de interés; la información difundida debe ser oportuna, confiable, relevante y suficiente. Para estos efectos, el directorio debe aprobar y supervisar estrategias y políticas generales de difusión, que consideren: a. información a difundir; b. medios de difusión; c. frecuencia y actualización de la información difundida; y d. proceso de control asociado a la difusión, incluyendo los medios para asegurar la calidad y suficiencia de esta.

Se establece, además, que las aseguradoras deben considerar los intereses y derechos de los asegurados en sus estructuras de gobierno corporativo ${ }^{76}$. En esta línea, el directorio debe lograr un equilibrio entre los deberes de los miembros del directorio hacia los accionistas y hacia los asegurados, y debe considerarlos en sus decisiones y definición de políticas. Así mismo, debe hacer un esfuerzo especial para entregar al asegurado la información que sea pertinente y apropiada a sus necesidades y hacerlo de manera comprensible para él; debe además procurar que los seguros que contrate sean adecuados para su situación particular. Por su parte, los asegurados deben tener acceso a adecuados mecanismos de consulta y reclamación ante la aseguradora.

Finalmente, las aseguradoras deben mantener a disposición de la SVS, toda la información necesaria para la evaluación del cumplimiento de los principios y buenas prácticas de gobierno corporativo señalados en la presente NCG $309^{77}$. Adicionalmente, las aseguradoras deberán realizar periódicamente una autoevaluación

76 La SVS publicó en julio de 2014 el documento de discusión Nuevo modelo de supervisión basado en riesgos de conducta de mercado, el cual sentaba las bases para un nuevo enfoque regulatorio y de supervisión para esta materia, tradicionalmente enfocada al cumplimiento de ciertas normas mínimas de operación, información y transparencia en la oferta de seguros. Chile, Superintendencia de Valores y Seguros, SVS, Principios básicos de conducta de mercado: desarrollo de un modelo de supervisión para la industria aseguradora (septiembre de 2015). Disponible en: http://www.svs.cl/portal/principal/605/articles-17329_doc_pdf.pdf

77 Si bien la SVS aún no ha emitido guías para el cumplimiento de los principios señalados ni - al parecer - ha terminado de desarrollar su metodología propia para la evaluación de riesgo de conducta de mercado en las compañías, este nuevo enfoque de supervisión no debe verse como lejano, ya que la SVS ha comenzado a aplicarlo en algunas de las normas que ha emitido. Un ejemplo claro en este sentido es la Circular 2180, que estableció un nuevo marco para la comercialización de seguros de vida con cuentas de inversión (CUI). Chile, Superintendencia de Valores y Seguros, SVS, Circular 2180, CIR 2180, Imparte instrucciones sobre comercialización de seguros con Cuenta Única de Inversión (CUI), 25 de junio de 2015. Disponible en: http://www.svs.cl/normativa/cir_2180_2015.pdf 
y enviar la información a la SVS. Este informe deberá contener al menos la siguiente información: a) una explicación del trabajo de autoevaluación realizado, que indique personas involucradas, apoyo de asesores externos, en caso de haberlos, horas aproximadas de trabajo, metodología, etc.; y b) el plan de acción definido, que indique las acciones concretas que la compañía adoptará respecto de cada brecha identificada. En caso que la compañía considere que una determinada brecha en la aseguradora se justifica por su modelo de negocio u otra razón, y por lo tanto no requiere una acción de cierre o mitigación de la brecha, deberá explicarlo detalladamente en este informe.

Luego de ser evaluada la puesta en marcha de la NCG 09, se le hicieron ajustes por medio de la NCG 408, de 31 de marzo de $2016^{78}$. Entre los cambios que incorpora la nueva normativa, y en el marco de la aplicación del modelo de Supervisión Basada en Riesgo (SBR), se introduce la exigencia a los directorios de las aseguradoras de formalizar la definición del apetito de riesgo de la compañía y la introducción del concepto de Autoevaluación de Riesgo y Solvencia (Own Risk and Solvency Assessment, ORSA) como parte del sistema de gestión de riesgo de la aseguradora. Al respecto, se establece que las compañías deben realizar una vez al año una autoevaluación de sus riesgos y solvencia, a objeto de evaluar su situación de solvencia actual y futura, conectando los requerimientos de capital proyectados a su plan de negocios y a los riesgos a los cuales está expuesta, para lo cual se establecen los aspectos metodológicos mínimos a considerar en la implementación del ORSA. Las compañías deberán enviar a más tardar el 30 de junio de cada año, un informe con sus resultados calculados al 31 de diciembre del año anterior, el cual deberá ser aprobado por el directorio de la aseguradora. Esta evaluación deberá estar sustentada en un proceso formalmente establecido, en el que estén documentados sus fundamentos, cálculos, resultados y planes de acción derivados de la evaluación. Se pretende que estos cambios normativos contribuyan a que Chile tenga un mercado de seguros

78 Chile, Superintendencia de Valores y Seguros, SVS, Norma de Carácter General 408, NCG 408, Modifica NCG 309, que establece principios de gobierno corporativo en entidades aseguradoras y reaseguradoras, 31 de marzo de 2016. Disponible en: http://www.svs.cl/normativa/ ncg_408_2016.pdf 
más desarrollado, con estándares y exigencias que siguen las mejores prácticas internacionales respecto de estas materias, lo que beneficia directamente a las empresas y a los asegurados.

Por último, se introduce el requisito de que las aseguradoras realicen cada dos años, una autoevaluación del grado de cumplimiento de sus estructuras de gobierno corporativo respecto de los principios establecidos en la NCG 309, referida al 31 de diciembre de cada año, y comunicar sus resultados a la Superintendencia junto al plan de acción que haya definido, a más tardar al 30 de junio del año siguiente. El informe - con los resultados de la autoevaluación y el plan de acción - deberá ser aprobado por el directorio de la compañía y enviado a la SVS de acuerdo al formato de presentación requerido descrito en el Anexo 1 de la norma [condiciones particulares (cotización), Póliza de seguro con cuenta única de inversión].

Resumidamente, este sistema establece que el plan de negocios de la compañía para el período proyectado debe estar formalmente establecido, aprobado y controlado por el directorio de la aseguradora, y reportar anualmente a la SVS sus resultados, con un informe que, de acuerdo a la norma, deberá contener una descripción detallada de la autoevaluación bajo un proceso formalmente establecido y documentado en sus fundamentos, cálculos, resultados y planes de acción derivados de esta. En cierta forma, el ORSA, que contempla tres etapas (evaluación, diseño y construcción), es la culminación de un proceso que empieza con la planificación estratégica de la compañía, que define líneas de negocio, límites de exposición, crecimiento esperado, política de inversiones, gestión operativa y otros aspectos, todo lo cual se traduce en riesgos asumidos por la aseguradora y en capital necesario para compensarlos. Desde un punto de vista regulatorio, es un elemento clave, por cuanto obliga a la compañía a incorporar como parte de su gestión, en forma explícita y cuantitativa, los conceptos de apetito de riesgo y capital asociado al riesgo; con ello se espera que las entidades puedan reconocer y gestionar oportunamente situaciones de toma excesiva de riesgos, y anticipar el impacto de determinados escenarios de estrés en sus operaciones.

Estas normativas representan un desafío cultural para las compañías de seguros con varias ventajas en pos de la optimización 
de los gobiernos corporativos. Las normas ofrecen flexibilidad y plantean autorregulación para el logro adecuado de estos objetivos.

\section{CONSTRUCCIÓN DE UNA PROPUESTA PARA LA APLICACIÓN DEL BUEN GOBIERNO CORPORATIVO A LAS SOCIEDADES NO COTIZADAS}

Volviendo al esquema general de sociedades anónimas no cotizadas, que no cuentan con una regulación especial de la SVS, hay dos caminos para regular esta materia: por medios impositivos o voluntarios. Para el primer caso, se requieren cambios legislativos de lege ferenda, mientras para el segundo basta la voluntad de los socios plasmada en sus estatutos sociales o en códigos de conducta (autorregulación). En tal sentido, nuestra propuesta es la siguiente:

Un marco normativo imperativo requiere estar bien fundado pues con ello se restringe la autonomía de la voluntad de las partes. En este caso, los intereses se deben centrar en aquellas materias que presentan un impacto relevante en la operatividad del mercado por los intereses colectivos que están en juego. En esta intelección, sería aconsejable establecer una disección entre sociedades no cotizadas con o sin responsabilidad limitada, siendo exigibles ciertas conductas solo a las primeras, pues las segundas tienen un resguardo mayor a partir del patrimonio de los socios. Por su parte, podría exigirse un tamaño mínimo de la sociedad en términos de capital o de facturación y/o el impacto en el mercado debido a las actividades que realiza la sociedad.

En este orden de ideas, se deben regular la administración y la dirección de estas sociedades, para exigir ciertos requisitos de operatividad y de funcionamiento, lo que nos lleva a la profesionalización de este órgano. La junta directiva debe contar con facultades de control y con responsabilidades claramente establecidas. Así mismo, se deben establecer con precisión sus derechos y obligaciones, por ejemplo, que los directores tienen un derecho-deber de ser informados oportuna y adecuadamente; que aquellos elegidos por un grupo o clase de accionistas tienen los mismos deberes para con la sociedad que los restantes directores; que los directores deben guardar reserva respecto de los negocios de la sociedad, y que tie- 
nen ciertas prohibiciones, como la de usar en beneficio propio o de terceros relacionados las oportunidades comerciales de que tuvieren conocimiento, entre otras medidas que privilegian el interés social frente a los intereses particulares.

En esta misma línea, deben regularse los deberes y derechos de los accionistas. En este contexto, sería pertinente brindar un tratamiento equitativo a las partes, que resguarde los intereses de aquellos y de la sociedad. Esto se traduce principalmente en normar ciertos derechos del socio, como el derecho de retiro de la sociedad (oportunidad y causales); las obligaciones del socio en relación con la sociedad (por ejemplo, lealtad); y las facultades de la sociedad en relación con el incumplimiento del socio (por ejemplo, derecho de exclusión), de manera tal que no haya diferencias a este respecto. Con estas medidas, se resguarda no solo el adecuado funcionamiento de la sociedad, previendo la solución de ciertos conflictos, sino también las expectativas de los acreedores.

En relación con las juntas de accionistas, no parece necesario establecer medidas impositivas de participación, toda vez que normalmente las sociedades no cotizadas tienen un grupo pequeño de socios o accionistas, de manera que la participación en la toma de decisiones no es problema mayor, razón por la que estas materias perfectamente pueden quedar entregadas a los estatutos o códigos, principalmente en lo que respecta a los socios controladores y las actividades con partes relacionadas.

En las restantes materias, sería aconsejable que las sociedades no cotizadas desarrollen códigos de conductas que se refieran a la estrategia de la empresa, para distinguir su misión, visión, valores, objetivos; señalar cuál es el modelo de gobierno corporativo adoptado, junto a los principios, políticas y marco normativo interno comprometido (reglamentos de la junta general y del consejo de administración, código ético, código de conducta, etc.); y determinar cuál es la cultura corporativa que asume, esto es, el modo efectivo de hacer las cosas, la relación con sus empleados y con los grupos de interés. En este caso, se puede establecer una regla análoga a la existente para las sociedades cotizadas, en cuanto a "Cumplir o explicar", de manera que la sociedad pueda pronunciarse sobre algunos temas de interés. 
Las sociedades podrían plantearse exigencias adicionales que se recojan en sus estatutos y pactos sociales, como la constitución de comisiones especializadas de control que auxilien al pleno del consejo en la supervisión de aquellas materias más delicadas por presentar mayor riesgo de conflicto de interés, la auditoría y el nombramiento de los consejeros; la conformación o designación de un consejero independiente (que tendría la virtud de introducir una perspectiva externa en materia de estrategia y supervisión, a lo que se une una visión objetiva e independiente a la de los propietarios, aportando nuevos conocimientos y capacidades a la empresa, para la utilidad en el orden interno de la sociedad); la retribución del consejo de administración; la gestión externa de los riesgos y una adecuada auditoría interna; la transparencia que obliga a las sociedades a facilitar periódicamente información sobre la situación financiera y sobre cualquier hecho susceptible de incidir en la marcha de la empresa; la presencia de la responsabilidad social corporativa, que implica que en la toma de decisiones empresariales no solo se atienda al interés de los socios e inversores, sino también a las expectativas de otros grupos con los que se relaciona la empresa. La consideración de intereses extrasocietarios que contribuyen al desarrollo y sostenibilidad de la empresa, además de favorecer su reputación y competitividad ${ }^{79}$; y el desarrollo de juntas de accionistas que permitan un adecuado sistema de toma de decisiones ${ }^{80}$.

Estas medidas, normativas y convencionales, ciertamente contribuirían a que las sociedades no cotizadas en Chile posean un mejor gobierno corporativo, lo que redundaría en la optimización del financiamiento, y la protección del mercado económico y financiero en general, lo que en última instancia se traduce en una mayor inversión y desarrollo.

79 Carlos Ignacio Gómez-Ligüerre, Responsabilidad civil y gobierno corporativo de la sociedad no cotizada, en Gobierno corporativo en sociedades no cotizadas, 225-245 (SANTIAGo HierroAnibarro, dir., Marcial Pons, Ediciones Jurídicas y Sociales, Madrid, Barcelona, Buenos Aires, São Paulo, 2014).

80 Jesús QuiJano-GonZález, Órganos de gobierno en la empresa familiar, en El patrimonio familiar, profesional y empresarial. Sus protocolos: constitución, gestión, responsabilidad, continuidad y tributación, Tomo VI, Estrategias de gobierno, continuidad y expansión de la empresa familiar, 47-92 (Martín Garrido-Melero \& Josep María Fugardo-Estivill, coords., Bosch S.A., Madrid, 2005). 


\section{CONCLUSIONES}

t. Un buen gobierno corporativo debe proveer incentivos para proteger los intereses de la sociedad, accionistas y los terceros vinculados, monitoreando la creación de valor, el uso eficiente de los recursos y brindando una transparencia de información. No se trata de un instrumento individual, sino más bien de un concepto que incluye el debate sobre las estructuras apropiadas de gestión y control de las empresas. También incluye las reglas que regulan las relaciones de poder entre los propietarios, el consejo de administración, la administración y, por último, pero no por ello menos importante, partes interesadas como los empleados, los proveedores, los clientes y el público en general.

u. La aplicación de los principios de buen gobierno corporativo a sociedades no cotizadas presenta beneficios relevantes: mejorar el sistema de financiamiento; la adopción de un mejor sistema de gestión interna de la sociedad capaz de generar un mayor valor respecto de terceros; y la prevención de conflictos o la solución anticipada de los mismos. Con todo, también enfrenta dos posibles problemas que se relacionan con la naturaleza del destinatario de la norma y su aplicación. Como señalamos atrás, las sociedades no cotizadas destinatarias de las recomendaciones de buen gobierno solo podrán ser empresas de una cierta entidad o dimensión, debido a los costos que ello implica, de manera que la adopción de estos PBGC requiere el análisis de estas ventajas de manera previa por sus socios. Por otra parte, una mirada rápida a los códigos de buen gobierno pone de manifiesto que el núcleo de su contenido estaría formado por recomendaciones relativas al consejo de administración, lo que inicialmente excluiría de su aplicación no solo al empresario individual, sino también a iniciativas empresariales más modestas.

v. En relación con la aplicación de los principios y los instrumentos a utilizar, debemos recordar la imposibilidad de formular recomendaciones de validez general. La aplicación de los principios de buen gobierno a las sociedades no cotizadas requiere valorar la necesidad de cada recomendación atendiendo a las circunstancias particulares, dimensión, actividad y madurez del negocio, de modo que sean los principios de buen gobierno los 
que se amolden a la empresa y no a la inversa. El motivo no es otro que evitar poner en riesgo la empresa. Por esta razón, no resulta extraño que los códigos de gobierno corporativo dirigidos a las sociedades no cotizadas contemplen un proceso gradual de implementación, dividido en varias fases y con alternativas que permitan adecuar las recomendaciones a su realidad. En algunos casos, más que de recomendaciones concretas, se trata de meras indicaciones a valorar por sus destinatarios, dado que en última instancia se trata de realizar un análisis de costes y beneficios que supone la aplicación de los principios de buen gobierno ${ }^{81}$.

w. Por otra parte, hemos de considerar que en las sociedades no cotizadas el conflicto potencial entre propiedad y control se manifiesta de distinta forma. En efecto, estas sociedades serán habitualmente sociedades cerradas y personalistas en que la condición de socio dependerá de la concurrencia de determinadas circunstancias personales y las empresas tendrán una dimensión más reducida que las cotizadas. Serán normalmente, con independencia de su forma legal, sociedades cuyos socios tendrán una difícil salida, pues la ausencia de un mercado objetivo y externo que valore su participación dificulta la determinación del precio que la sociedad o el resto de accionistas deben pagarles a cambio de sus acciones o participaciones.

x. No se trata solo de extender los PBGC a las sociedades no cotizadas, para que ello sea eficiente, deben estudiarse las necesidades concretas de la sociedad en particular, para luego determinar en qué medida y qué instrumento será el adecuado para el logro satisfactorio de esta implementación.

81 En España, la Ley 24/1988 de mercado de valores obliga a las sociedades cotizadas a elaborar un informe anual de gobierno corporativo que deberá ser comunicado a la Comisión Nacional del Mercado de Valores, como también respecto a la política de remuneración de sus directivos. España, Ley 24/1988, de 28 de julio, del Mercado de Valores, 181 Boletín Oficial del Estado, BOE, 29 de julio de 1988. Disponible en: http://www.boe.es/buscar/act.php?id=BOEA-1988-18764. En todos los casos, los mecanismos de información y de publicidad buscan poner a disposición de accionistas inversores y acreedores el seguimiento del código de buen gobierno corporativo de las sociedades cotizadas. Todos ellos promueven que las sociedades cotizadas se doten de mecanismos adecuados de organización interna y de control y gestión de los riesgos que asumen y se sitúan en línea de las iniciativas del resto de los estados miembros de la Unión Europea; sin embargo, nada prevén para las sociedades no cotizadas. SANTIAGO Hierro-Anibarro \& Marta Zabaleta-Díaz, Buen gobierno corporativo de la pyme y de la empresa familiar en la Unión Europea, en Gobierno corporativo en sociedades no cotizadas (Marcial Pons, Madrid, Barcelona, Buenos Aires, São Paulo, 2014). 
y. Finalmente, en relación con el caso chileno, vemos que si bien hay un precedente relevante para extender los principios de gobierno corporativo a sociedades no cotizadas, como ocurre con la ley de sociedades anónimas cerradas, también advertimos que en otras materias no hay una regulación completa o simétrica. Proponemos extender los principios de gobierno corporativo vía legislativa y voluntaria, y distinguir para ello ciertas materias. Considerando que las sociedades, con independencia de su tipo, son los sujetos más relevantes del mercado, estas medidas podrán redundar en un mejoramiento de las confianzas, mayor protección a los inversores y acreedores, y con ello un mejor desarrollo del mercado en general. 


\section{BIBLIOGRAFíA}

\section{Libros}

Abousaid, SAnaA, Manual IFC de Gobierno de Empresas Familiares (Corporación Financiera Internacional, IFC, Banco Mundial, Washington, 2008). Disponible en: http://www-wds.worldbank.org/external/default/WDSContentServer/WDSP/ IB/2008/08/21/000333038_20080821025522/Rendered/PDF/450770WP0Box331si ness1200801PUBLIC1.pdf

Berle, Adolf A. \& Means, Gardiner D., The Modern Corporation and Private Property (MacMillan, New York, 1932).

Comisión Europea, $\operatorname{COM(2010)~} 284$ final, Libro Verde. El gobierno corporativo en las entidades financieras y las políticas de remuneración (Comisión Europea, Bruselas, 2 de junio de 2010). Disponible en: http://eur-lex.europa.eu/LexUriServ/ LexUriServ.do?uri=COM:2010:0284:FIN:ES:PDF

Comisión Europea, $\operatorname{COM(2011)~} 164$ final, Libro Verde. La normativa de gobierno corporativo de la Unión Europea (Comisión Europea, Bruselas, 2011). Disponible en: http://ec.europa.eu/internal_market/company/docs/modern/com2011-164_ es.pdf, http://ec.europa.eu/internal_market/company/docs/modern/com2011164_en.pdf

Comisión Europea, COM(2010) 561 final, Libro Verde, Política de auditoría: lecciones de la crisis (Comisión Europea, Bruselas, 13 de octubre de 2010). Disponible en: https://publications.europa.eu/es/publication-detail/-/publication/087440532f56-415a-a985-7ceaef3d3b3a/language-es

GARrido, José MARÍA, La distribución y el control del poder en las sociedades cotizadas y los inversores institucionales (Publicaciones Real Colegio de España en Bolonia, Zaragoza, 2002).

Hierro-Anibarro, Santiago, coord., Estudios de derecho de sociedades y del mercado de valores, Libro homenaje a Klaus J. Hopt (Marcial Pons, Ediciones Jurídicas y Sociales, Madrid, 2010).

Instituto de Consejeros Administradores, ICA, Principios de buen gobierno corporativo para empresas no cotizadas: código de buenas prácticas para el consejo, los consejeros y administradores (Instituto de Consejeros Administradores, ICA, Madrid, diciembre de 2005). Disponible en: http://www.ecgi.org/codes/ documents/ica_cgp_non_listed_2006_es.pdf

McCahery, Joseph A. \& Vermeulen, Erik P. M., Corporate Governance of Non-Listed Companies (Oxford University Press, OUP, Oxford, 2008).

Organisation for Economic Co-operation and Development, OECD, Corporate Governance of Non-Listed Companies in Emerging Markets (Organisation for Economic Co-operation and Development, OECD, Paris, 2006). Disponible en: http://www.oecd.org/daf/ca/corporategovernanceprinciples/ corporategovernanceofnon-listedcompaniesinemergingmarkets.htm

Organisation for Economic Co-operation and Development, OECD, G/20 OECD Principles of Corporate Governance (Organisation for Economic Co-operation and Development, OECD, Paris, 2014). Disponible en: http://www.oecd.org/to 
pic/0,3373,en_2649_34813_1_1_1_1_37439,00.html

Organización para la Cooperación y el Desarrollo Económicos, OCDE, Principios de gobierno corporativo (Organización para la Cooperación y el Desarrollo Económicos, OCDE, París, 2004). Disponible en: http://www.oecd.org/daf/ca/ corporategovernanceprinciples/37191543.pdf

SÁncheZ-Calero, Fernando, Los administradores en las sociedades de capital (Thomson Civitas, Madrid, 2005).

Vásquez-Palmar, María Fernanda, Sociedades (Thomson Reuters, Santiago, 2013).

\section{Colaboración en obras colectivas}

Bascuñán-Rodríguez, Antonio, La regulación de la información privilegiada en el mercado de valores después de la ley $N^{\circ} 20.382$, en Gobiernos corporativos. Aspectos esenciales de las reformas a su regulación, 87-137 (JAVIER WiLENMANn, coord., Universidad Adolfo Ibáñez, Abeledo Perrot, Thomson Reuters, Santiago, 2011).

Crespo-Espert, José Luis; Crecente-Romero, Fernando \& Mir-Fernández, Carlos, Gobierno corporativo de las sociedades no cotizadas desde la perspectiva de la economía financiera, en Gobierno corporativo en sociedades no cotizadas, 247-324 (Santiago Hierro-Anibarro, dir., Marcial Pons, Ediciones Jurídicas y Sociales, Madrid, Barcelona, Buenos Aires, São Paulo, 2014).

Enriques, Luca; Hansmann, Henry \& Kraakman, Reinier, The Basic Governance Structure: The Interest of Shareholders as a Class, en The Anatomy of Corporate Law. A Comparative and Functional Approach ( $2^{\text {nd }}$ ed., ReInIER KraAKman, JoHn Armour, Paul Davies, Luca Enriques, Henry B. Hansmann, Gérard Hertig, Klaus J. Hopt, Hideki Kanda \& Edward B. Rock, Oxford University Press, OUP, Oxford, 2010).

Gómez-Ligüerre, Carlos Ignacio, Responsabilidad civil y gobierno corporativo de la sociedad no cotizada, en Gobierno corporativo en sociedades no cotizadas, 225-245 (Santiago Hierro-Anibarro, dir., Marcial Pons, Ediciones Jurídicas y Sociales, Madrid, Barcelona, Buenos Aires, São Paulo, 2014).

Hierro-Anibarro, Santiago, Gobierno corporativo sin mercado de valores, en Gobierno corporativo en sociedades no cotizadas, 17-33 (SAntiago Hierro-Anibarro, dir., Marcial Pons, Ediciones Jurídicas y Sociales, Madrid, Barcelona, Buenos Aires, São Paulo, 2014).

Hierro-Anibarro, Santiago, La politica comunitaria de simplificación del derecho de sociedades, en Simplificar el derecho de sociedades, 65-109 (SAntiago HierroAnibarro, dir., Marcial Pons, Ediciones Jurídicas y Sociales, Madrid, Barcelona, Buenos Aires, São Paulo, 2010).

Hierro-Anibarro, Santiago \& Zabaleta-Díaz, Marta, Buen gobierno corporativo de la pyme y de la empresa familiar en la Unión Europea, en Gobierno corporativo en sociedades no cotizadas (Marcial Pons, Madrid, Barcelona, Buenos Aires, São Paulo, 2014)..

IsLas-Rojas, Gonzalo, Gobierno corporativo: teoría económica, principios de la OCDE y la Ley $N^{\circ} 20.382$, en Gobiernos corporativos. Aspectos esenciales de las reformas 
a su regulación, 9-44 (JAVIER WiLENMANN, coord., Universidad Adolfo Ibáñez, Abeledo Perrot, Thomson Reuters, Santiago, 2011).

Lagos-Villarreal, Osvaldo, Reformas al gobierno de las sociedades contenidas en la ley $N^{o}$ 20.382. Un gesto al equilibrio, en Gobiernos corporativos. Aspectos esenciales de las reformas a su regulación, 45-79 (JAVIER WiLENMANN, coord., Universidad Adolfo Ibáñez, Abeledo Perrot, Thomson Reuters, Santiago, 2011).

Quijano-GonzÁlez, Jesús, Gobierno corporativo. Administración de sociedades mercantiles y responsabilidad, en Gobierno corporativo y responsabilidad social de las empresas, 91-127 (Elena F. Pérez-Carrillo, coord., Marcial Pons, Ediciones Jurídicas y Sociales, Barcelona, 2009).

QuiJano-GonzÁlez, Jesús, Órganos de gobierno en la empresa familiar, en El patrimonio familiar, profesional y empresarial. Sus protocolos: constitución, gestión, responsabilidad, continuidad y tributación, Tomo VI, Estrategias de gobierno, continuidad y expansión de la empresa familiar, 47-92 (MARTín GARRIDO-MELERO \& Josep María Fugardo-Estivill, coords., Bosch S.A., Madrid, 2005).

VÁsquez-Palma, María Fernanda, Una aproximación a los modelos existentes en materia de Gobiernos Corporativos y la elección de Chile a partir de las reformas incorporadas por la Ley 20.832, en Jornadas Chileno-Uruguayas de Derecho Comercial, 143-155 (Librotecnia, Santiago, 2011).

ZABALETA-DíAz, MARTA, La experiencia comparada de gobierno corporativo en sociedad no cotizada, en Gobierno corporativo en sociedades no cotizadas, 83-144 (SANTIAGO Hierro-Anibarro, dir., Marcial Pons, Ediciones Jurídicas y Sociales, Madrid, Barcelona, Buenos Aires, São Paulo, 2014).

\section{Revistas}

AlCalde-Rodríguez, EnRiQue, Uso de información privilegiada: algunas consideraciones sobre el sentido y alcance de la prohibición en relación con su sujeto, objeto y sanción, 27 Revista Chilena de Derecho, 1, 11-28 (2000). Disponible en: https:// dialnet.unirioja.es/servlet/articulo?codigo $=2650196$

FArrar, John, The New Financial Architecture and Effective Corporate Governance, 33 The International Lawyer, 4, 927-954 (1999).

Gómez-Ansón, Silvia; Fernández, Carlos \& Fernández-Álvarez, Ana Isabel, El papel supervisor del consejo de administración sobre la actuación gerencial. Evidencia para el caso español, 22 Investigaciones Económicas, 501-516 (1998).

Hucke, Anja \& Just, Susan, Die Anwendbarkeit des DCGK auf nicht börsennotierte Unternehmen Welche Standards sollten Sekundäradressaten übernehmen?, 2 Zeitschrift für Corporate Governance: ZCG; Leitung und Überwachung in der Unternehmens- und Prüfungspraxis, 5-12 (2007).

Jensen, Michael C. \& Meckling, William H., Theory of the Firm: Managerial Behavior, Agency Costs and Ownership Structure, 3 Journal of Financial Economics, 4, 305-360 (1976). Disponible en: http://www.sciencedirect.com/science/article/ pii/0304405X7690026X

Kitagawa, Carlos Enrique; Ribeiro, Maisa de Souza \& Ciampaglia-Nardi, Paula 
Carolina, The Responsibilities of the Board: The Level of Compliance of Latin Americans' Companies to the OECD principles of Corporate Governance, 9 Research in Accounting in Emerging Economies, 97-117 (2009).

Lefort, Fernando \& Urzúa, Francisco, Board Independence Firm Performance and Ownership Concentration: Evidence from Chile, 61 Journal of Business Research, 615-622 (2008). Disponible en: http://papers.ssrn.com/sol3/papers.cfm?abstract_ $\mathrm{id}=1664074$

Lefort, Fernando \& Walker, Eduardo, The Effects of Economics and Political Shocks on Corporate Governance Systems in Chile, 2 Revista Abante, 2, 183-206 (2000). Disponible en: https://ideas.repec.org/a/pch/abante/v2y2000i2p183-206.html, http://eacc10.puc.cl/files/ABT/Contenidos/Vol-2-N2/5\%20Walker\%20Lefort.pdf

MacNeil, Iain, The Trajectory of Regulatory Reform in the UK in the Wake of the Financial Crisis, 11 European Business Organization Law Review, EBOR, 4, 483-526 (2010). Disponible en: http://eprints.gla.ac.uk/41807/1/41807.pdf

Pagano, Marco \& Volpin, Paolo F., The Political Economy of Corporate Governance, 95 The American Economic Review, 1005-1030 (2005).

Prado-Puga, Arturo, Acerca del concepto de información privilegiada en el mercado de valores chileno: su alcance, contenido y límites, 30 Revista Chilena de Derecho, 2, 237-269 (2003). Disponible en: https://dialnet.unirioja.es/descarga/ articulo/2650285.pdf

Shleifer, Andrei \& Vishny, Robert W., A Survey of Corporate Governance, 52 Journal of Finance, 2, 737-783 (1997). Disponible en: http://scholar.harvard.edu/files/ shleifer/files/surveycorpgov.pdf

Thomas, M. Sava B., Gobierno corporativo en los Estados Unidos a comienzos del siglo XXI y su posición en el ámbito global, 29 Revista Chilena de Derecho, 3, Actas de las I Jornadas de Derecho de la Empresa, Santiago, 24-25 de octubre de 2001 (septiembre-diciembre de 2002), 661-671 (2002). Disponible en: https://dialnet. unirioja.es/servlet/articulo?codigo $=2650251$

VÁsquez-Palma, María Fernanda, Revisión del ámbito de aplicación subjetivo y objetivo de la noción de uso de información privilegiada en Chile: un examen de la normativa a la luz de las tendencias doctrinales y jurisprudenciales, 17 Revista de Derecho, Universidad Católica del Norte, Coquimbo, 2, 239-297 (2010). Disponible en: http:// www.redalyc.org/articulo.oa?id=371041341010

\section{Working paper}

García, Rodrigo, Norma de información sobre prácticas de gobierno corporativo en Chile (Superintendencia de Valores y Seguros, Working paper, Santiago de Chile, 2014). Disponible en: https://www.svs.cl/portal/publicaciones/610/ articles-16379_doc_pdf.pdf

QUINTANA, JAVIER, Guía práctica para el buen gobierno de las empresas familiares (Instituto de la Empresa Familiar, IEF, Documento 165, Madrid, 2012). Disponible en: http://www.iefamiliar.com/web/es/destacados/guia-practica-para-el-buengobierno-de-las-empresas-familiares.pdf 
Tapia-Hermida, Alberto Javier, Las sociedades cotizadas: noción y estatuto jurídico (Universidad Complutense de Madrid, Departamento de Derecho Mercantil, Facultad de Derecho, Documento de Trabajo 26, Madrid, 2010). Disponible en: http://eprints.ucm.es/9896/1/A.J._Tapia._Sociedades_Cotizadas.pdf

\section{Tratados internacionales}

Organización para la Cooperación y el Desarrollo Económicos, OCDE, Convención de Lucha contra la corrupción de Agentes Públicos Extranjeros en las Transacciones Comerciales Internacionales, 21 de noviembre de 1997. Disponible en: https:// www.oecd.org/daf/anti-bribery/ConvCombatBribery_Spanish.pdf

\section{Leyes y nornativa internacional}

Alemania, Código alemán de gobierno corporativo (Deutscher Corporate Governance Kodex, DCGK, German Corporate Governance Code, as amended on May 5, 2015 with decisions from the plenary meeting of May 5, 2015). Disponible en: http:// www.dcgk.de/de/kodex.html, http://www.dcgk.de/en/code.html

Austria, Código austriaco de gobierno corporativo (Österreichischer Corporate Governance Kodex, 2012, Austrian Code of Corporate Governance as amended in January 2015). Disponible en: http://www.corporate-governance.at/kodex.htm, http://www.corporate-governance.at/pdf/CG_Kodex_EN_Jaenner_2015_v3.pdf

Bélgica, Código belga de gobierno corporativo (Belgian Code on Corporate Governance, 9 December 2004). Disponible en: http://www.corporategovernancecommittee. be/en/about-2009-code/2009-belgian-code-corporate-governance

España, Código de Buen Gobierno de las Sociedades Cotizadas, CBGSC (Comisión Nacional del Mercado de Valores, CNMV, Madrid, febrero de 2015). Disponible en: http://www.cnmv.es/docportal/publicaciones/codigogov/codigo_buen_ gobierno.pdf

España, Ley 24/1988, de 28 de julio, del Mercado de Valores, 181 Boletín Oficial del Estado, BOE, 29 de julio de 1988. Disponible en: http://www.boe.es/buscar/act. php?id=BOE-A-1988-18764

España, Ley 31/2014, de 3 de diciembre, por la que se modifica la Ley de Sociedades de Capital para la mejora del gobierno corporativo, 293 Boletín Oficial del Estado, $B O E$, 4 de diciembre de 2014. Disponible en: https://www.boe.es/diario_boe/txt. php?id=BOE-A-2014-12589

Reino Unido, The UK Corporate Governance Code (The Financial Reporting Council Limited, London, April 2016). Disponible en: https://www.frc.org.uk/Our-Work/ Publications/Corporate-Governance/UK-Corporate-Governance-CodeApril-2016.pdf 


\section{Legislación chilena}

Chile, Código de Comercio, Diario Oficial, 23 de noviembre de 1865. Disponible en: https://www.leychile.cl/Navegar?idNorma $=1974$

Chile, DFL 251 de 1931, compañías de seguros, sociedades anónimas y bolsas de comercio, Diario Oficial, 22 de mayo de 1931. Disponible en: https://www.leychile. cl/Navegar?idNorma $=5201$

Chile, DL 3538 de 1980, crea la Superintendencia de Valores y Seguros, Diario Oficial, 23 de diciembre de 1980. Disponible en: http://www.leychile.cl/ Navegar?idNorma $=7168$

Chile, Ley 1712 de 1904, reglamenta el funcionamiento de las compañías de seguros, Diario Oficial, 19 de noviembre de 1904. Disponible en: http://www.leychile.cl/ Navegar?idNorma $=22868$

Chile, Ley 4228 de 1927, Diario Oficial, 21 de diciembre de 1927. Disponible en: http:// www.leychile.cl/Navegar?idNorma $=24585$

Chile, Ley 4404 de 1928, crea la Inspección General de Sociedades Anónimas y Operaciones Bursátiles, Diario Oficial, 10 de septiembre de 1928. Disponible en: http://www.leychile.cl/Navegar?idNorma $=24712$

Chile, Ley 18045, Ley de mercado de valores, LMV, Diario Oficial, 22 de octubre de 1981. Disponible en: http://www.leychile.cl/Navegar?idNorma=29472

Chile, Ley 18046, Ley sobre sociedades anónimas, LSA, Diario Oficial, 22 de octubre de 1981. Disponible en: http://www.leychile.cl/Navegar?idNorma=29473

Chile, Ley 19705 regula la oferta pública de adquisición de acciones (OPAS) y establece régimen de gobiernos corporativos, 36.842 Diario Oficial, 20 de diciembre de 2000. Disponible en: http://www.leychile.cl/Navegar?idLey $=19705$

Chile, Ley 20382 introduce perfeccionamientos a la normativa que regula los gobiernos corporativos de las empresas, 39.498 Diario Oficial, 29 de octubre de 2009. Disponible en: http://www.leychile.cl/Navegar?idNorma=1007297

Chile, Superintendencia de Valores y Seguros, SVS, Circular 2180, CIR 2180, Imparte instrucciones sobre comercialización de seguros con Cuenta Única de Inversión (CUI), 25 de junio de 2015. Disponible en: http://www.svs.cl/normativa/ cir_2180_2015.pdf

Chile, Superintendencia de Valores y Seguros, SVS, Norma de Carácter General 30, NCG 30, Establece normas de inscripción de emisores y valores de oferta pública en el registro de valores, su difusión, colocación y obligaciones de información consiguientes (SAA, EVOP Y EIRV), 10 de noviembre de 1989. Disponible en: http://www.svs.cl/normativa/ncg_30_1989.pdf

Chile, Superintendencia de Valores y Seguros, SVS, Norma de Carácter General 273, NCG 273, Regula sistemas de votacion en juntas de accionistas, 13 de enero de 2010. Disponible en: http://www.svs.cl/normativa/ncg_273_2010.pdf

Chile, Superintendencia de Valores y Seguros, SVS, Norma de Carácter General 309, NCG 309, Principios de gobierno corporativo y sistemas de gestión de riesgo y control interno, 20 de junio de 2011. Disponible en: http://www.svs. $\mathrm{cl} /$ institucional/mercados/ver_archivo.php?archivo=/web/compendio/ncg/ 
ncg_309_2011.pdf

Chile, Superintendencia de Valores y Seguros, SVS, Norma de Carácter General 325, NCG 325, Imparte instrucciones sobre sistema de gestión de riesgos de las aseguradoras y evaluación de solvencia de las compañías por parte de la Superintendencia. Deroga NCG 130 de 2002, 29 de diciembre de 2011. Disponible en: http://www.svs.cl/institucional/mercados/ver_archivo.php?archivo=/web/ compendio/ncg/ncg_325_2011.pdf

Chile, Superintendencia de Valores y Seguros, SVS, Norma de Carácter General 341, NCG 341, Establece normas para la difusión de información respecto de los estándares de gobierno corporativo adoptados por las sociedades anónimas abiertas, 29 de noviembre de 2012. Disponible en: http://www.svs.cl/normativa/ ncg_341_2012.pdf

Chile, Superintendencia de Valores y Seguros, SVS, Norma de Carácter General 385, NCG 385, Establece normas para la difusión de información respecto de las prácticas de gobierno corporativo adoptados por las sociedades anónimas abiertas. Deroga norma de carácter general 341 de 2012, 8 de junio de 2015. Disponible en: http://www.svs.cl/normativa/ncg_385_2015.pdf

Chile, Superintendencia de Valores y Seguros, SVS, Norma de Carácter General 386, NCG 386, Modifica norma de carácter general 30 de 1989 en los términos que indica, 8 de junio de 2015. Disponible en: http://www.svs.cl/normativa/ ncg_386_2015.pdf

Chile, Superintendencia de Valores y Seguros, SVS, Norma de Carácter General 408, NCG 408, Modifica NCG 309, que establece principios de gobierno corporativo en entidades aseguradoras y reaseguradoras, 31 de marzo de 2016. Disponible en: http://www.svs.cl/normativa/ncg_408_2016.pdf

\section{Casos}

Chile, Corte Suprema, Tercera Sala, Causa 4261/2004, Resolución 13925, 7 de julio de 2005, MacKenna Echaurren, Luis Fernando y otros con Superintendencia de Valores y Seguros, Recursos de casación en el fondo y en la forma. Extracto disponible en: http://corte-suprema-justicia.vlex.cl/vid/-255182466

\section{Comunicaciones, documentos, guías, investigaciones, recomendaciones, reportes}

Chile, Superintendencia de Valores y Seguros, SVS, Principios básicos de conducta de mercado: desarrollo de un modelo de supervisión para la industria aseguradora (septiembre de 2015). Disponible en: http://www.svs.cl/portal/principal/605/ articles-17329_doc_pdf.pdf

Chile, Superintendencia de Valores y Seguros, SVS, Informe final. Fortalecimiento de estándares de gobierno corporativo de las sociedades anónimas abiertas (Superintendencia de Valores y Seguros, SVS, Santiago, junio de 2015). Disponible en: http://www.svs.cl/portal/principal/605/articles-20924_doc_pdf.pdf 
Colombia, Superintendencia de Sociedades, Cámara de Comercio de Bogotá \& Confecámaras, Guía colombiana sobre gobierno corporativo para sociedades cerradas y de familia (Superintendencia de Sociedades, Cámara de Comercio de Bogotá \& Confecámaras, Bogotá, septiembre de 2009). Disponible en: http://www. supersociedades.gov.co/inspeccion-vigilancia-y-control/gobierno-corporativoy-rse/cartillas-y-guias/Cartillas $\% 20 \mathrm{y} \% 20$ Guias/guia $\% 20$ colombiana $\% 20 \mathrm{de} \% 20$ gobierno $\% 20$ corporativo $\% 20(8)$.pdf

Comisión de las Comunidades Europeas, Recomendación 2003/361/CE de la Comisión, 6 de mayo de 2003, sobre la definición de microempresas, pequeñas y medianas empresas, L 124/36 Diario Oficial de la Unión Europea, 20 de mayo de 2003. Disponible en: http://eur-lex.europa.eu/legal-content/ES/ TXT/?uri $=$ celex $\% 3 \mathrm{~A} 52003 \mathrm{DC} 0284$

Comisión de las Comunidades Europeas, COM (2003), p. 284 final, 21 de mayo de 2003, Comunicación de la Comisión al Consejo y al Parlamento Europeo, Modernización del Derecho de sociedades y mejora de la gobernanza empresarial en la Unión Europea. Un plan para avanzar (Comisión Europea, 2003). Disponible en: http://ec.europa.eu/transparency/regdoc/?fuseaction=list\&coteId= 1 \&year $=2003 \&$ number $=284 \&$ language $=\mathrm{es}$

Comisión de las Comunidades Europeas, COM/2012/0740 final, Comunicación de la Comisión al Parlamento Europeo, al Comité Económico y Social Europeo y al Comité de las Regiones, Plan de acción, Derecho de sociedades europeo y gobierno corporativo, Un marco jurídico moderno para una mayor participación de los accionistas y la viabilidad de las empresas (Comisión de las Comunidades Europeas, Estrasburgo, 12 de diciembre de 2012). Disponible en: http://eur-lex. europa.eu/legal-content/ES/TXT/?uri=CELEX\%3A52012DC0740

Corporación Andina de Fomento, CAF, Manual de Gobierno Corporativo para empresas de capital cerrado (Corporación Andina de Fomento, CAF, Caracas, 2010). Disponible en: http://publicaciones.caf.com/media/25371/gc_capital_cerrado_2. pdf

España, Comisión Especial para el Estudio de un Código Ético de los Consejos de Administración de las Sociedades, El gobierno de las sociedades cotizadas, Informe Olivencia (Manuel Olivencia-Ruiz, dir, Madrid, 26 de febrero de 1998). Disponible en: http://observatoriorsc.org/informe-olivencia/

España, Comisión Especial para el Fomento de la Transparencia y Seguridad en los Mercados y Sociedades Cotizadas, Informe Aldama (EnRiQue de Aldama y MiÑón, presidente, 8 de enero de 2003). Disponible en: http://www.cnmv.es/ DocPortal/Publicaciones/CodigoGov/INFORMEFINAL.PDF

España, Comisión Nacional del Mercado de Valores, CNMV, Grupo Especial de Trabajo, Código Unificado de Buen Gobierno, CUBG (Comisión Nacional del Mercado de Valores, CNMV, Madrid mayo de 2006). Disponible en: http://www. cnmv.es/DocPortal/Publicaciones/CodigoGov/Codigo_unificado_Esp_04.pdf

European Confederation of Director's Associations, ecoDa, Corporate Governance Guidance and Principles for Unlisted Companies in Europe (ecoDa, Brussels, 2010). Disponible en: http://ecoda.org/uploads/media/GUIDANCE_-_2010_ CG_for_Unlisted_-_EU.pdf

European Private Equity \& Venture Capital Association, EVCA, Corporate Governance 
Guidelines: Guidelines and Good Practice in Management of Privately Held Companies in the Private Equity and Venture Capital Industry (2005, Actualización 2009). Disponible en: http://www.investeurope.eu/uploadedFiles/Home/Toolbox/ Industry_Standards/evca_corporate_governance_guidelines_2010.pdf

Financial Reporting Council, London Stock Exchange \& The Committee on the Financial Aspects of Corporate Governance, Report of the Committee on The Financial Aspects of Corporate Governance, Cadbury Report [sir Adrian Cadbury] (May 1992). Disponible en: http://cadbury.cjbs.archios.info/report

Garicano-Rojas, Tomás \& Hafner, Pablo, Recomendaciones de buen gobierno corporativo para empresas no cotizadas (Centro de Buen Gobierno, Madrid, 2016). Disponible en: http://www.centrobuengobierno.ie.edu/wp-content/uploads/sites/87/2013/11/ Recomendaciones-Buen-Gobierno-Empresas-No-cotizadas-actualizado.pdf

Hafner, Pablo, Iniciativas públicas y privadas de códigos de buen gobierno para empresas no cotizadas en Europa (Centro de Buen Gobierno IE/GT, Iberdrola, IE, Mutua Madrileña \& PwC, Madrid, 2015). Disponible en: http://www. centrobuengobierno.ie.edu/2016/04/01/iniciativas-publicas-y-privadas-decodigos-de-buen-gobierno-para-empresas-no-cotizadas-en-europa/

Organización para la Cooperación y el Desarrollo Económicos, OCDE, Líneas directrices de la OCDE para empresas multinacionales (Organisation for Economic Co-operation and Development, OECD, OECD Publishing, Paris, 1976, 2011). Disponible en: http://www.oecd.org/daf/inv/mne/48004323. pdf, http://mneguidelines.oecd.org/text/, http://www.oecd.org/daf/inv/mne/ MNEguidelinesESPANOL.pdf

Paz-Ares, Cándido, Deberes fiduciarios y responsabilidad de los administradores (reflexiones sobre la reforma legal en Latinoamérica) (Organisation for Economic Co-operation and Development, OECD, in co-operation with the World Bank Group, The Third Meeting of the Latin American Corporate Governance Roundtable, Mexico, 8-10 April 2002). Disponible en: http://www.oecd.org/ corporate/ca/corporategovernanceprinciples/2576714.pdf

\section{Direcciones web}

http://centrogobiernocorporativo.uc.cl/proyectos-de-investigacion.html

http://www.svs.cl/portal/principal/605/articles-20924_doc_pdf.pdf

https://www.worldbank.org/ifa/rosc.html 